\title{
Manganese Oxide Nanoparticles As MRI Contrast Agents In Tumor Multimodal Imaging And Therapy
}

This article was published in the following Dove Press journal:

International Journal of Nanomedicine

\author{
Xiaoxia Cai \\ Qingxia Zhu \\ Yun Zeng (D) \\ Qi Zeng (D) \\ Xueli Chen (iD) \\ Yonghua Zhan 1 \\ Engineering Research Center of \\ Molecular and Neuro Imaging of the \\ Ministry of Education, School of Life \\ Science and Technology, Xidian \\ University, Xi'an, Shaanxi, People's \\ Republic of China
}

\begin{abstract}
Contrast agents (CAs) play a crucial role in high-quality magnetic resonance imaging (MRI) applications. At present, as a result of the Gd-based CAs which are associated with renal fibrosis as well as the inherent dark imaging characteristics of superparamagnetic iron oxide nanoparticles, Mn-based CAs which have a good biocompatibility and bright images are considered ideal for MRI. In addition, manganese oxide nanoparticles (MONs, such as MnO, $\mathrm{MnO}_{2}, \mathrm{Mn}_{3} \mathrm{O}_{4}$, and $\mathrm{MnO}_{\mathrm{x}}$ ) have attracted attention as T1-weighted magnetic resonance $\mathrm{CAs}$ due to the short circulation time of $\mathrm{Mn}$ (II) ion chelate and the size-controlled circulation time of colloidal nanoparticles. In this review, recent advances in the use of MONs as MRI contrast agents for tumor detection and diagnosis are reported, as are the advances in in vivo toxicity, distribution and tumor microenvironment-responsive enhanced tumor chemotherapy and radiotherapy as well as photothermal and photodynamic therapies.
\end{abstract}

Keywords: manganese oxide nanoparticles, MRI, multimodal imaging, contrast agent, tumor therapy

\section{Introduction}

Molecular imaging technology is of great value for tumor detection and prognosis monitoring as a result of its high accuracy and reliability for elucidating biological processes and monitoring disease conditions. ${ }^{1,2}$ Various imaging techniques which are currently in widespread use include optical imaging (OI), X-ray computed tomography (CT), positron emission tomography/single photon emission computed tomography (PET/SPECT), magnetic resonance imaging (MRI), and ultrasound (US) imaging, while multimodal imaging technologies including photoacoustic (PA) tomography are being developed..$^{3-5}$

Among these techniques, MRI has become one of the most powerful means of clinical detection and prognosis observation as a result of its non-invasive, high spatial resolution, non-ionizing radiation, and soft tissue contrast. ${ }^{6}$ While MRI is the best imaging technique for detecting soft tissue, the long relaxation time of water protons leads to weak differences between tissues, resulting in poor image depiction between typical and malignant tissue. ${ }^{7}$ Fortunately, magnetic resonance contrast agent (CA) has the ability to enhance contrast, thereby improving the sensitivity of magnetic resonance diagnosis. Approximately $35 \%$ of the clinical magnetic resonance scans require the use of CAs. ${ }^{8}$ Therefore, in order to obtain high-quality molecular imaging for clinical diagnosis, many researchers have explored the CAs of MRI. ${ }^{9}$

In order to improve imaging contrast sensitivity, various T1- or T2-MRI CAs based on gadolinium $(\mathrm{Gd})$, manganese $(\mathrm{Mn})$, and iron oxide nanoparticles $\left(\mathrm{Fe}_{3} \mathrm{O}_{4}\right.$
Correspondence: Yonghua Zhan Molecular and Neuro Imaging of the Ministry of Education, School of Life Science and Technology, Xidian University, Xi'an, Shaanxi 71007I, People's Republic of China

Tel +862981891070

Fax +862981891060

Email yhzhan@xidian.edu.cn 
NPs) have been developed. ${ }^{10}$ Gd-based T1 CAs in the form of ionic complexes have been extensively used in clinical practice. ${ }^{11}$ However, usual small size complex-based agents tend to suffer from short blood circulation time and distinct toxicity in vivo, which has the potential to cause nephrogenic systemic fibrosis and cerebral deposition. ${ }^{12-14}$ Researchers have turned to superparamagnetic nanoparticles, especially $\mathrm{Fe}_{3} \mathrm{O}_{4}$ NPs. In the past 20 years, a few T2 CAs based on $\mathrm{Fe}_{3} \mathrm{O}_{4}$ NPs have entered clinical trials or been approved by US Food and Drug Administration. ${ }^{15}$ Unfortunately, these nanoparticles have been somewhat limited in their clinical application due to their intrinsic dark signals and susceptibility artifacts in MRI, which means it is difficult to make a distinction between small early stage tumors and hypointense areas. ${ }^{16,17}$ Therefore, Mn-based CAs are considered ideal substitutes due to their bright signals and good biocompatibility.

Mn-based CAs can be divided into two major categories: $\mathrm{Mn}^{2+}$ composites and manganese oxide nanoparticles (MONs). Unfortunately, $\mathrm{Mn}^{2+}$ complexes have short blood circulation times ${ }^{18}$ while high doses of $\mathrm{Mn}^{2+}$ can accumulate in the brain, causing manganese poisoning to manifest as changes in central nervous system activity, resulting in cognitive, psychiatric, and movement abnormalities. ${ }^{19-21}$ As a result, $\mathrm{Mn}^{2+}$ chelate is not an ideal candidate for an MR CA. However, MONs emerging in recent years have exhibited negligible toxicity ${ }^{22}$ and good T1-weighted contrast effects. ${ }^{23}$ Surprisingly, these MONs can respond to tumor microenvironments (TME), such as $\mathrm{pH}, \mathrm{H}_{2} \mathrm{O}_{2}$ or glutathione (GSH), in order to enhance MRI, alleviate tumor hypoxia and enhance therapy treatment. ${ }^{24}$ Therefore, MONs have been extensively studied in the field of magnetic resonance CAs.

In recent years, the relaxivity and toxicological properties of $\mathrm{MONs}^{25}$ as well as the chemistry and magnetic resonance performance of responsive Mn-based CAs have been reviewed. ${ }^{26}$ However, according to the current literature, few reviews have been conducted specifically on the progress of MONs in both tumor imaging and enhanced therapeutic effect in the past six years. Therefore, in this review, we divided MONs into four categories: $\mathrm{MnO}$, $\mathrm{Mn}_{3} \mathrm{O}_{4}, \mathrm{MnO}_{2}$, and $\mathrm{MnO}_{\mathrm{x}}$ and reviewed their achievements as MR CAs in MRI, bimodal and multimodal imaging as well as imaging-guided tumor therapy, respectively. This review also covers surface modification, toxicity in vitro and in vivo, and the tumor microenvironment-responsive performance of MONs-based materials.

\section{MnO-Based Nanoparticles In Tumor Diagnosis And Therapy}

$\mathrm{Mn}$ (II) ion is a key factor which is necessary for MnOs to have strong MRI ability, as the five unpaired electrons in its $3 \mathrm{~d}$ orbital can produce a large magnetic moment and cause nearby water proton relaxation. ${ }^{25}$ This means that MnO NPs are potential candidates for T1-weighted MR CAs. Surface coating is a common method for improving the relaxation rate of $\mathrm{MnO} \mathrm{NPs}$, such as polymer functionalization, ${ }^{27,28}$ silica coating, ${ }^{29}$ phospholipid modification, ${ }^{30}$ and so on. Additionally, researchers have recently integrated MnO NPs with other modal CAs or nanotheranostic agents to provide more comprehensive information for clinical research. Table 1 highlights some examples based on $\mathrm{MnO}$ nanoparticles as imaging CAs and nanotheranostic agents in vivo.

\section{MnO As Contrast Agents In Magnetic Resonance Imaging}

With the advantages of small volume, easy preparation, and low toxicity, MnO nanoparticles are good T1 CAs. However, $\mathrm{MnO}$ nanoparticles may be retained by the reticuloendothelial system and subsequently enriched in the liver and spleen, leading to $\mathrm{Mn}^{2+}$-induced toxic effects. In order to reduce the toxicity of $\mathrm{MnO}$ in vivo, Chevallier and colleagues attached pegylated bis-phosphonate dendrons (PDns) to the surface of $\mathrm{MnO}$, which greatly improved colloidal stability, relaxation performance $\left(\mathrm{r}_{1}=4.4 \mathrm{mM}^{-1} \mathrm{~s}^{-1}, \mathrm{r}_{2}=37.8 \mathrm{mM}^{-1} \mathrm{~s}^{-1}, 1.41 \mathrm{~T}\right)$ and rapid excretion ability. In addition, the $\mathrm{MnO}$ nanoparticles with a hydrodynamic diameter of $13.4 \pm 1.6 \mathrm{~nm}$ were eventually discharged through the hepatobiliary pathway as feces, urinary excretion, and so on. ${ }^{31}$

Polyethylene glycol (PEG) coating has the potential to significantly improve the biocompatibility and physiological stability of nanoparticles and can also be conjugated with specific polypeptides and other aptamers in order to greatly improve the targeting capacities of nanoparticles. Therefore, PEG-modified $\mathrm{MnO}$ has been favored by many researchers. As an example, PEG-MnO NPs with a hydrodynamic diameter of $15.08 \pm 2.67 \mathrm{~nm}$ synthesized by $\mathrm{Li}$ and colleagues had a T1 relaxation rate of $12.942 \mathrm{mM}^{-1} \mathrm{~s}^{-1}$ and a low $\mathrm{r}_{2} / \mathrm{r}_{1}$ ratio of 4.66 at $3.0 \mathrm{~T}$, three times that of clinically used Gd-based CAs. ${ }^{27}$ In addition, the AS1411 aptamer introduced by covalent cross-linking not only confers the PEG-MnO nanoprobe's ability to target 786-0 renal cancer tumor cells but can also prolong the storage time of the probe in tumor cells. Huang and 
Table I Representative Examples Of MnO-Based Nanoparticles As Contrast Agents And Nanotheranostic Agents In Vivo

\begin{tabular}{|c|c|c|c|c|}
\hline \multicolumn{5}{|c|}{ Single Mode Imaging Contrast Agents } \\
\hline Materials & Targets & Imaging Modality & Animal Model & Reference \\
\hline mPEG\&cRGD-g-PAsp@MnO & cRGD & TI-MRI & A549 tumor-bearing mice & 28 \\
\hline PEG-MnO & ASI4II & TI-MRI & 786-0 tumor-bearing mice & 27 \\
\hline MnO-TETT-FA & folic acid & TI-MRI & Tiny brain glioma bearing mice & 34 \\
\hline MnO modified with PEG & RGD & TI-MRI & M2I tumor-bearing mice & 33 \\
\hline MnO@PVP & 1 & TI-MRI & Healthy KM mice & 35 \\
\hline mPEG-SA-DA@MnO & 1 & TI-MRI & A 4-week male ICR mouse & 32 \\
\hline MnO@PDns & 1 & TI-MRI & Healthy balb/c female mice & 31 \\
\hline \multicolumn{5}{|c|}{ Multimodal imaging contrast agents } \\
\hline Materials & Targets & Imaging Modality & Animal Model & Reference \\
\hline $\mathrm{Fe}_{3} \mathrm{O}_{4} @ \mathrm{MnO} / \mathrm{mSiO}_{2}-\mathrm{CDI} 33$ & $\mathrm{CD} \mid 33$ & TI- and T2-MRI & Adult Sprague-Dawley rats & 37 \\
\hline $\mathrm{Fe}_{3} \mathrm{O}_{4} / \mathrm{MnO}-\mathrm{Cy} 5.5-\mathrm{CTX}$ & CTX & NIRF/TI- and T2-MRI & Glioma-bearing mice & 44 \\
\hline MnO-PEG-Cy5.5 & 1 & NIRF/TI-MRI & Glioma-bearing nude mice & 40 \\
\hline MnO-TETT & 1 & Fluorescence/TI-MRI & Glioma-bearing mice & 42 \\
\hline MnO@Au & 1 & TI-MR/PA/CT Imaging & $\mathrm{HepG}_{2}$-bearing mice & 45 \\
\hline Au@HMSN/Au\&MnO-PEI & 1 & US/MR/CT Imaging & VX2 tumor-bearing rabbits & 2 \\
\hline \multicolumn{5}{|l|}{ Nanotheranostic agents } \\
\hline Materials & $\begin{array}{l}\text { Treatment } \\
\text { agents }\end{array}$ & Imaging-guided treatment & Animal model & Reference \\
\hline MnO@CNSs & CNSs & MRI-guided PTT & $4 \mathrm{TI}$ tumor-bearing $\mathrm{BABL} / \mathrm{c}$ mice & 14 \\
\hline MWNTs-MnO-PEG & MWNTs & MR and dark dye imaging-guided PTT & Mice exhibiting LNs metastases & 53 \\
\hline IR808@MnO & IR808 & NIR fluorescence/PA/MR imaging-guided PTT & MCF-7 cell tumor-bearing nude mice & 54 \\
\hline MnO and DTX co-loaded & DTX & $M R$ and fluorescence imaging-guided & Human breast cancer MDA-MB-23I & 52 \\
\hline PTNPs & & chemotherapy & tumor-bearing mice & \\
\hline USMO@MSNs-Dox & Dox & MRI-guided chemotherapy & HeLa cells-bearing $B A B L / c$ nude mice & 51 \\
\hline
\end{tabular}

Abbreviations: mPEG, methoxypolyethylene glycols; cRGD, cyclic arginine-glycine-aspartic acid; PAsp, poly(aspartic acid); mPEG\&cRGD-g-PAsp, mPEG and cRGD-grafted PAsp; MRI, magnetic resonance imaging; PEG, poly (ethylene glycol); TETT, N-(trimethoxysilylpropyl) ethylene diamine triacetic acid; FA, folic acid; RGD, arginine-glycineaspartic acid; PVP, poly(vinylpyrrolidone); mPEG-SA-DA, dopamine-terminated mPEG linked with succinic anhydride; PDns, pegylated bis-phosphonate dendrons; mSiO ${ }_{2}$, mesoporous silica; CTX, chlorotoxin; NIRF, near-infrared fluorescence; PA, photoacoustic; CT, X-ray computed tomography; HMSN, hollow mesoporous silica nanoparticle; PEI, polyethylenimine; US, ultrasound; CNSs, carbonaceous nanospheres; PTT, photothermal therapy; MWNTs, multi-walled carbon nanotubes; DTX, docetaxel; PTNPs, polymeric theranostic nanoparticles; USMO@MSNs, ultrasmall manganese oxide-capped mesoporous silica nanoparticles; Dox, doxorubicin.

colleagues coated $\mathrm{MnO}$ nanoparticles with dopaminefunctionalized PEG (mPEG-SA-DA). ${ }^{32}$ They verified that this approach can achieve the best hydrophilicity and higher longitudinal relaxation rate $\left(16.14 \mathrm{mM}^{-1} \mathrm{~s}^{-1}\right)$ when coating density reaches $6.51 \mathrm{mmol} \mathrm{m}^{-2}$. In order to enhance probe targeting, mPEG\&cRGD-g-PAsp@MnO nanoparticles $\left(r_{1}=10.2 \mathrm{mM}^{-1} \mathrm{~s}^{-1}, \mathrm{r}_{2}=62.3 \mathrm{mM}^{-1} \mathrm{~s}^{-1}, 3 \mathrm{~T}\right)$ were obtained by conjugating $\mathrm{MnO}$ nanoparticles and poly (aspartic acid)-based graft polymer (containing PEG and 3,4-dihydroxyphenylacetic acid groups) before being conjugated with cRGD. ${ }^{28}$ And the hydrodynamic diameter of the conjugated nanoparticles was about $100 \mathrm{~nm}$ with a polydispersity index of 0.24 . The nanoprobe was high targeting and was capable of accumulating in tumors and prolonging blood circulation time. Similarly, Gallo et al functionalized $\mathrm{MnO}$ nanoparticles with PEGylated RGD peptides in order to target the tumor overexpressing $\alpha_{\mathrm{v}} \beta_{3}$ integrin. ${ }^{33}$ The $r_{1}$ and $r_{2}$ values were calculated to be 1.44 $\mathrm{mM}^{-1} \mathrm{~s}^{-1}$ and $3.98 \mathrm{mM}^{-1} \mathrm{~s}^{-1}$ at $9.4 \mathrm{~T}$, respectively. They also investigated the effect of PEG chain length on MR imaging. These authors found that long-chain PEG molecules (5000 DaI) have the potential to lead to a higher accumulation of high integrin tumors over a long period of time (24 hours) than short-chain PEG (600 DaI).

In addition, magnetic nanomaterials have been demonstrated to couple with mesoporous silicon, noble metals, carbon-based materials, and fluorophores to function more efficiently. Li et al coated $\mathrm{MnO}$ nanoparticles with carboxymethyl dextran (CMDexMONPs $)\left(r_{1}=0.44 \mathrm{mM}^{-1} \mathrm{~s}^{-1}, \mathrm{r}_{2}=3.45 \mathrm{mM}^{-1} \mathrm{~s}^{-1}, 3.0\right.$ 
T). ${ }^{17}$ Chen and colleagues improved the water solubility of $\mathrm{MnO}$ through the use of transesterified oleic acid with $\mathrm{N}$-(trimethoxysilylpropyl) ethylenediamine triacetic acid (TETT) silane. ${ }^{34} \mathrm{Hu}$ et al coated polyvinylpyrrolidone (PVP) on MnO NPs using layer-bylayer electrostatic assembly. In particular, MnO@PVP NPs can pass through the blood-brain barrier (BBB) and gradually metabolize to other sites with blood flow. This is indicated as an intravascular MRI CA $\left(\mathrm{r}_{1}=1.937\right.$ $\left.\mathrm{mM}^{-1} \mathrm{~s}^{-1}, \mathrm{r}_{2}=27.879 \mathrm{mM}^{-1} \mathrm{~s}^{-1}, 3.0 \mathrm{~T}\right)$ and a potential application in basic neuroscience research. ${ }^{35}$ Hsu et al encapsulated MONPs with silica-F127 $\quad\left(\mathrm{PEO}_{106}\right.$ $\mathrm{PPO}_{70} \mathrm{PEO}_{106}$ ) in order to make them highly hydrophilic. In addition, under the same conditions, the porous silica-PEO nanocoating layer has the ability to enhance the contrast of $\mathrm{T} 1 \quad\left(\mathrm{r}_{1}=1.17 \mathrm{mM}^{-1} \mathrm{~s}^{-1}, \quad \mathrm{r}_{2}=30.73\right.$ $\left.\mathrm{mM}^{-1} \mathrm{~s}^{-1}, 7.0 \mathrm{~T}\right)$ when compared to PEG-phospholipids, dense silica, and mesoporous silica. ${ }^{29}$ In addition, the structure of $\mathrm{MnO}$ can affect its relaxation properties. Octagonal $\mathrm{MnO}$ nanoparticles have a larger surface area than spherical nanoparticles of the same size, resulting in significant enhancement of low-temperature ferromagnetic behavior. Therefore, the $\mathrm{r}_{1}$ value of the $85 \mathrm{~nm}$ polyethylene glycol dopamine ( $\mathrm{PEG}_{600}$-DPA) coated octahedral $\mathrm{MnO}$ nanoparticles at a concentration of $0.194 \mathrm{mM}$ is similar to that of the $17 \mathrm{~nm}$ spherical nanoparticles at a concentration of $0.254 \mathrm{mM}^{36}$

\section{MnO As MR Contrast Agents In Bimodal And Multimodal Imaging}

Malignant tumors pose a serious threat to human health. Improving accurate diagnosis of tumors remains a challenging problem. In order to simultaneously obtain a tumor's overall and local image information, as well as to realize the integration of preoperative and intraoperative diagnosis and treatment, multimodal imaging has become a research hotspot and an area for future development due to its ability to integrate various imaging modes.

T1-weighted images can be used to highlight anatomical structures, while T2-weighted images are more suitable for pathological recognition. T1-T2 dual-mode imaging combination is able to significantly improve MRI efficiency. The contrast effect of the T1-T2 dual-mode contrast agent is distance-dependent. To avoid signal quenching, the distance between T1 NPs and T2 NPs is greater than $20 \mathrm{~nm}$. Nowadays, different methods for combining $\mathrm{MnO}$ (T1 CA) and $\mathrm{Fe}_{3} \mathrm{O}_{4}$ (T2 CA) in order to construct T1-T2 dual-mode contrast agents (DMCAs) have been extensively studied. For example, Peng and colleagues synthesized $\mathrm{Fe}_{3} \mathrm{O}_{4} @ \mathrm{MnO} / \mathrm{mSiO}_{2} \mathrm{NPs}$ by loading $\mathrm{MnO}$ into the core-shell pores of $\mathrm{Fe}_{3} \mathrm{O}_{4} @ \mathrm{mSiO}_{2}{ }^{37}$ They found that when the $\mathrm{MnO}$ cluster was bound to the nanoeffect zone of $\mathrm{Fe}_{3} \mathrm{O}_{4}$, local induction of DMCAs can be adjusted by altering the size of $\mathrm{Fe}_{3} \mathrm{O}_{4}$ to reduce the damage of MRI to host cells. In order to verify this conclusion, they coupled an anti-CD133 antibody to the surface of $\mathrm{Fe}_{3} \mathrm{O}_{4} @ \mathrm{MnO} / \mathrm{mSiO}_{2}$ for live brain cell imaging. Results showed a higher T1-T2 contrast imaging effect and no local damage under strong MRI magnetic field. Mn-doped $\mathrm{Fe}_{3} \mathrm{O}_{4}$ and $\mathrm{MnO}$ magnetic nanoparticles were then co-loaded onto an oxidized graphene (GO) sheet as T1 and T2 MR CA. ${ }^{38}$ The distance between MnO NPs and $\mathrm{Fe}_{3} \mathrm{O}_{4}$ NPs was greater than $20 \mathrm{~nm}$ for avoiding signal quenching.

Due to the reliability and utility of both MRI and optical imaging dual-mode in tumor diagnosis and treatment, optical/magnetic resonance dual-mode probes which are based on $\mathrm{MnO}$ nanoparticles have flourished. Zheng et al obtained an MR/near-infrared imaging bimodal nanoprobe (MnO-Cy5.5) by conjugating a near-infrared (NIR) dye Cy5.5 to the MnO surface. The probe was effective in infarcted myocardium accumulates. The colocalization of near-infrared fluorescence (NIRF) imaging with leukocytes and macrophages in the infarcted area means that it is a potential tool for accurate quantitative infarct areas. ${ }^{39}$ Similarly, Chen and colleagues synthesized the MnO-PEG-Cy5.5 probe, which can enhance the T1 contrast of large-volume glioma imaging. ${ }^{40} \mathrm{Hsu}$ et al encapsulated both coumarin-545T (C545T) and $\mathrm{MnO}$ nanoparticles mixed loading into silica nanoshells in order to obtain a pH-responsive fluorescence and MRI dual-mode probe (MCNCs). Under neutral conditions, $\mathrm{MnO}$ nanoparticles have a fluorescence quenching effect for C545T, while in an acidic environment, the dissolution of $\mathrm{MnO}$ nanoparticles into $\mathrm{Mn}^{2+}$ leads to a 7-fold increase in $\mathrm{T} 1$ contrast and fluorescence recovery. In addition, the further coupling of the dual-mode probe with folic acid (FA) conferred the ability of MCNCs to target tumor cells and delayed fluorescence recovery, resulting in an enhanced target background signal ratio and higher sensitivity after activation. ${ }^{41}$

Some methods which do not use fluorescent dye have been introduced. Lai et al found that $\mathrm{MnO}$ which has been obtained through the thermal decomposition of an excess of oleic acid (oleic acid: manganese content $>2$ ) displays 
fluorescence excitation characteristics across its entire visible spectrum. ${ }^{42}$ To verify its bio-imaging performance, C6 cells were detected following surface modification of TETT, and it was found that cells exhibited blue and green fluorescence at $405 \mathrm{~nm}$ and $458 \mathrm{~nm}$, respectively. Additionally, the longitudinal relaxation rate $\left(r_{1}\right)$ at $7 \mathrm{~T}$ was $4.68 \mathrm{mM}^{-1} \mathrm{~s}^{-1}$. Interestingly, Banerjee et al accidentally discovered the formation of a fluorophore when heat-treating pyrrolidin-2-one modifying $\mathrm{MnO} .{ }^{43}$ Cell experiments initially suggested that these $\mathrm{MnO}$ nanoparticles support bioluminescence imaging, although the exact luminescent substances remain unclear.

Multi-modal probes enable simultaneous multi-source image processing, which results in more accurate information. In order to minimize the imaging impact of each of the components, the structure and components of the entire probe must be carefully designed. $\mathrm{Li}$ and colleagues synthesized $\mathrm{Fe}_{3} \mathrm{O}_{4} / \mathrm{MnO}-\mathrm{Cy} 5$.5-CTX NPs for NIRF and T1-/T2-MR multimodal imaging in vitro and in vivo. The CTX (chlorotoxin) is a glioma ligand. ${ }^{44}$ Zhang et al designed a highly efficient US/MR/CT multimodal probe (Au@HMSN/Au\&MnO). ${ }^{2}$ Large-sized Au nanoparticles were positioned in the cavity of the hollow mesoporous silica nanoparticles (HMSNs), while small-sized $\mathrm{Au}$ and $\mathrm{MnO}$ are evenly distributed in the mesoporous shell. The grayscale increment from HMSN to Au@HMSN/ Au\&MnO (46.9) was much larger than the sum of HMSN to HMSN/MnO (9.9) and Au@HMSN/Au (22.5), achieving $1+1 \geq 2$ of ultrasonic performance. Specifically, the polyethyleneimine (PEI)-modified Au@HMSN/ Au\&MnO-PEI ${ }_{1800}$ demonstrated no obvious cytotoxicity in vitro and in vivo within 30 days. In vivo evaluation experiments found that the probe accumulated in large numbers $(6.39 \%)$ in rabbit liver VX2 tumors. In addition, the contrast of US imaging was significantly enhanced, while the MR signal intensity of VX2 tumors increased from 63 to 87 and the HU value of CT increased from 75 to 130 , which was much larger than that of a typical liver. Liu et al reported a tumor microenvironment (TME)responsive $\mathrm{MR} / \mathrm{PA} / \mathrm{CT}$ trimodal tumor imaging $\mathrm{CA}$, namely $\mathrm{MnO}$ nanocrystals wrapped in porous gold nanoclusters $(\mathrm{MnO} @ \mathrm{Au} \mathrm{NCs}){ }^{45} \mathrm{PA}$ imaging has noninvasive, high-resolution, and accurate quantification in the detection of tumor pathophysiological statuses such as microvessel density, blood oxygen saturation, and hemodynamics. ${ }^{46}$ However, the PA imaging visualization area is small. CT imaging has the characteristics of wholebody imaging and tissue-free penetration depth limitation, but it cannot distinguish the subtle differences between soft tissues. ${ }^{47}$ Magnetic resonance imaging is the best choice for soft tissue detection. Therefore, combined $\mathrm{MR} / \mathrm{PA} / \mathrm{CT}$ multi-mode imaging on a nano-platform enables more accurate tumor diagnosis. This porous layer can retard the release of $\mathrm{Mn}^{2+}$ to enhance $\mathrm{T} 1$ contrast and increase PA imaging depth. Following the injection of $\mathrm{MnO} @ \mathrm{Au} \mathrm{NCs}$ into HepG2 tumor-bearing mice, the PA signal was significantly enhanced and subcutaneous microvessels in the depth range of $3.5-9.3 \mathrm{~mm}$ were clearly observed. An intratumoral injection of $\mathrm{MnO} @ \mathrm{Au} \mathrm{NCs}$ in vivo CT imaging studies was performed. The HU value at the tumor site increased from 115.3 to 657.1 . Results showed that this strategy has a satisfactory enhancement effect on MR/PA/CT tumor imaging.

\section{MnO As MR Contrast Agents In Imaging- Guided Tumor Therapy}

Nanomedicine has the ability to greatly increase the dose and accuracy of targeted drug delivery to reduce toxic side effects, meaning it can treat tumors more effectively under non-invasive conditions. The loading of therapeutic drugs or combination of some clinical therapies to achieve simultaneous diagnosis and treatment of tumors has been extensively studied. $\mathrm{MnO}$ has some unique advantages for treating tumors. Water-dispersible manganese oxide nanocrystals which have been obtained by microwave-assisted methods can induce true autophagy and are independent of P53 activation. ${ }^{48}$ This autophagy enhancement helps manganese oxide nanocrystals to synergize with chemotherapeutic drugs in order to produce greater lethality against tumors. The triphenylphosphonium $\left(\mathrm{PPh}_{3}\right)$ is able to explore mitochondrial membrane potential. $\mathrm{MnO} @ \mathrm{SiO}_{2}-$ $\mathrm{PPh}_{3}{ }^{+} \mathrm{NPs}$ with mitochondrial targeting were efficiently taken up by HeLa cells. ${ }^{49}$ This probe is highly specific for mitochondria. It induces severe cytotoxicity within four hours and causes cancer cell death.

In terms of combined chemotherapy, Howell and colleagues synthesized multifunctional lipid nanoparticles (MLMNs) by encapsulating $\mathrm{MnO}$ in mixed cation micelles. ${ }^{50}$ In vitro studies found that M-LMNs which had been loaded with doxorubicin (Dox) or plasmid DNA was efficiently ingested by Lewis Lung Cancer (LLC1). Following intranasal administration, M-LMNs were preferentially aggregated in the lung, while MRI and release of DNA and Dox could be simultaneously performed. This suggests great potential in the treatment of lung cancer. $\mathrm{MnSO}_{4}$-terminated 
mesoporous silica nanoparticles (MSNs) were calcined to obtain USMO@MSNs nanocrystals with adjustable pore sizes. The USMO@MSNs pore size was adjusted to 1.42 $\mathrm{nm}$ to match the chemotherapeutic drug Dox $(1.37 \mathrm{~nm})$, while the loading capacity was $456 \mathrm{mg} / \mathrm{g}$. In the weak acidic environment of tumors, a simultaneous release of $\mathrm{Mn}^{2+}$ and Dox enabled real-time monitoring of the chemotherapy efficacy of Dox by MRI. ${ }^{51}$ Abbasi et al coloaded the anticancer drug docetaxel (DTX) and $\mathrm{MnO}$ nanoparticles into an amphiphilic polymer which contained fluorescent dyes. ${ }^{52}$ The longitudinal relaxation $\left(r_{1}=2.4\right.$ $\mathrm{mM}^{-1} \mathrm{~s}^{-1}$ ) of the probe was 2.7 times higher than that of MnO NPs. In contrast, fluorescence imaging had a positive long-term effect and could effectively load and sustain DTX, reducing the dose of drug needed to inhibit the growth of human breast cancer cells by 3-4.4 times.

In terms of photothermal therapy, MnO-coated carbon nanotubes (MWNTs-MnO-PEG) were used for the photothermal therapy of metastatic tumors. In order to examine the therapeutic effect of the nanotheranostic agent, it was co-incubated with A549 (human lung cancer) cells, after which it was found that under the laser irradiation of $3 \mathrm{w} / \mathrm{cm}^{2}$, almost no cells survived and typical cells were not significantly reduced. Lymph nodes (LNs) metastatic mouse model of A549 cells was used for in vivo studies. The surface temperature of lymph nodes increased rapidly from $25.28^{\circ} \mathrm{C}$ to $55.64^{\circ} \mathrm{C}$ within 5 mins under laser irradiation, while the surrounding typical tissues did not increase significantly. ${ }^{53}$ Similarly, Xiang et al encapsulated $\mathrm{MnO}$ with carbon nanospheres to obtain $\mathrm{MnO} @ \mathrm{CNSs}$ (CNSs) with MR imaging and photothermal therapy performance. ${ }^{14}$ In order to enhance the phototherapy effect, Zhou and colleagues synthesized a mitochondria-targeted multifunctional nano-photosensitizer (IR808@MnO NP), utilizing IR808 as a tumor-targeting ligand. Under laser irradiation, IR808 converts $\mathrm{O}_{2}$ to highly toxic ${ }^{1} \mathrm{O}_{2}$ and also produces high heat. The tumors of MCF-7 nude mice treated with IR808@MnO NPs were completely attenuated under 808 nm near-infrared light. ${ }^{54}$

\section{$\mathrm{Mn}_{3} \mathrm{O}_{4}$-Based Nanoparticles In Tumor Diagnosis And Therapy}

The development of $\mathrm{Mn}_{3} \mathrm{O}_{4}$ NPs as MR CAs has also received extensive attention from researchers. In $\mathrm{Mn}_{3} \mathrm{O}_{4}$ NPs, Mn exhibits a mixed valence of +2 and +3 . Compared with divalent manganese ions, higher valence states of Mn tend to exhibit lower effective T1 relaxation due to fewer unpaired electrons and less electron spin relaxation time. However, high-valent manganese ions can be activated in an intracellular reducing environment by GSH, while Mn ions are generated to increase the T1 relaxation rate. ${ }^{55}$ Thereby, a redox-activated $\mathrm{T} 1$ magnetic resonance $\mathrm{CA}$ can be designed.

\section{$\mathrm{Mn}_{3} \mathrm{O}_{4}$ As Contrast Agents In Magnetic Resonance Imaging}

In recent years, multiple $\mathrm{Mn}_{3} \mathrm{O}_{4}$-based nanoplatforms have been developed for MRI as T1 CAs. In particular, the improvement of $\mathrm{Mn}_{3} \mathrm{O}_{4}$ T1-relaxivity and biocompatibility through different surface modifications has attracted interest from researchers. Encapsulation of hydrophobic nanoparticles by polymers - including PEG, PEI, and polydopamine (PDA) - is currently the most common modification strategy (see Figure 1A). Examples of the PEG-modified method include $\mathrm{Hu}$ et al's design of the aptamer (AS1411) conjugated $\mathrm{Mn}_{3} \mathrm{O}_{4} @ \mathrm{SiO}_{2}$ core-shell nanoprobes which was used for targeted T1-MRI in mice with human cervical cancer, after which the in vivo quantitative biological distribution and the toxicity of the probe were evaluated. ${ }^{56}$ Probes with a T1-relaxivity of $0.53 \mathrm{mM}^{-1} \mathrm{~s}^{-1}$ were modified on the surface of $\mathrm{SiO}_{2}$ shelly by PEG to improve their biocompatibility. Yang and colleagues synthesized monodisperse manganese oxide NPs with a coating of silica (abbreviated as $\mathrm{Mn}_{3} \mathrm{O}_{4} @ \mathrm{SiO}_{2}$ ) via pyrolysis at the high temperature and were aminated through the use of silylation. ${ }^{57}$ PEG was coupled to an $\mathrm{Mn}_{3} \mathrm{O}_{4} @ \mathrm{SiO}_{2}$ surface via the amino-group attachment, followed by chemical grafting of targeting ligand FA to PEG. The final nanoprobes demonstrated good colloidal stability in RMPI plus $10 \%$ fetal bovine and exhibited the ability to target T1 magnetic resonance imaging in HeLa cells and HeLa animal tumor models overexpressing FA receptors. Wang and coworkers synthesized antifouling manganese oxide NPs using the solvothermal method in the presence of trisodium citrate, after which they modified the surface with PEG and L-cysteine. ${ }^{58}$ The prepared NPs had a high T1-relaxivity of $3.66 \mathrm{mM}^{-1} \mathrm{~s}^{-1}$ at $0.5 \mathrm{~T}$, good aqueous solution dispersibility, good colloidal stability, and good biocompatibility. More crucially, the modification of L-cysteine allowed NPs to have a longer blood circulation time (half decay time of 28.4 hours) than those without the L-cysteine modification (18.5 hours) as well as reduced macrophages cellular uptake. This allowed NPs to 


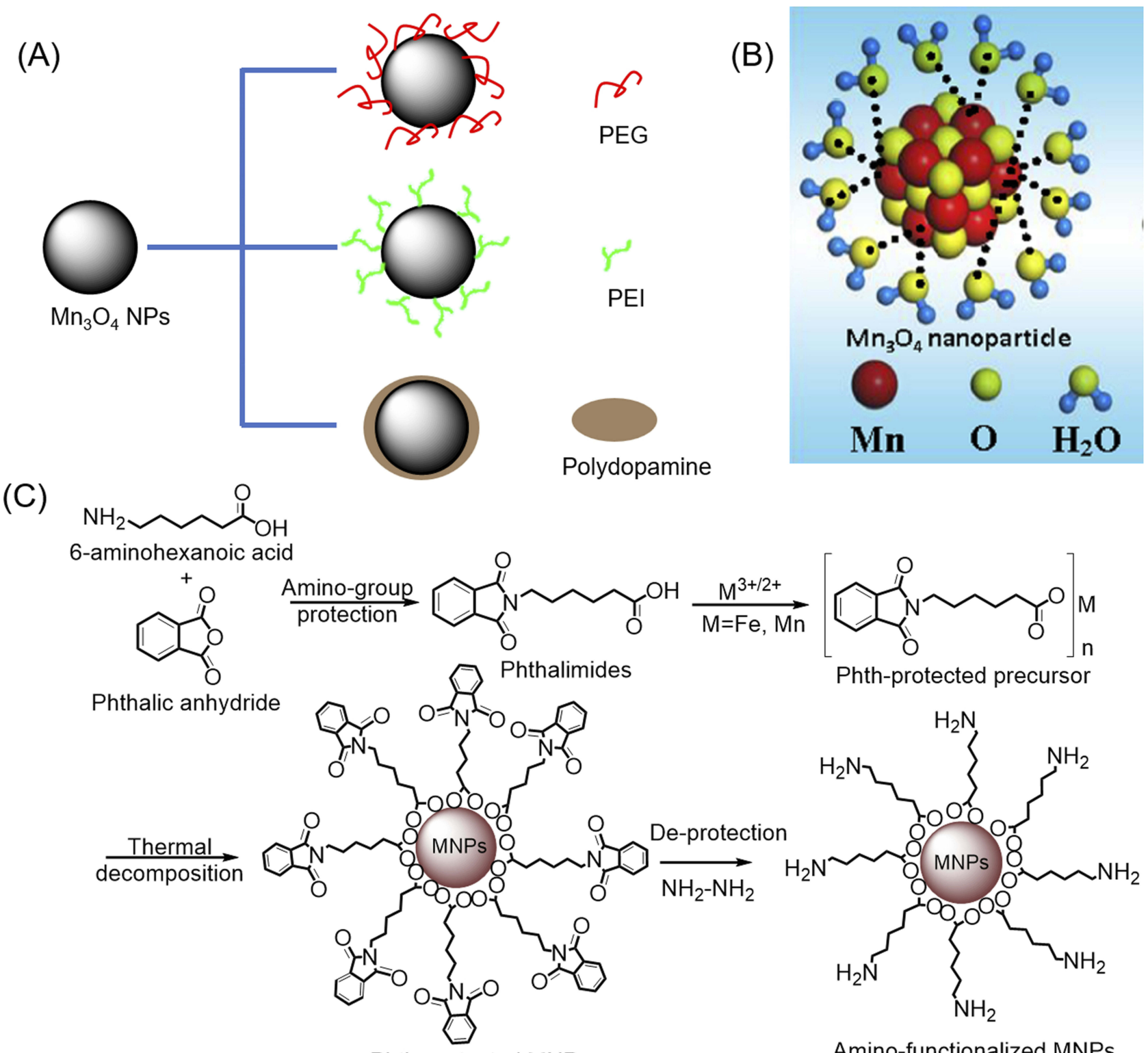

Phth-protected MNPs

Amino-functionalized MNPs

Figure I (A) Common modification strategy for improving the TI relaxation rate and biocompatibility of $\mathrm{Mn}_{3} \mathrm{O}_{4} \mathrm{NPs}_{\text {. }}(\mathbf{B}) \mathrm{Schematic}$ illustration of the interaction between $\mathrm{Mn}_{3} \mathrm{O}_{4} \mathrm{NPs}$ synthesized by liquid laser ablation and water. Reproduced from Xiao J, Tian XM, Yang C, et al. Ultrahigh relaxivity and safe probes of manganese oxide nanoparticles for in vivo imaging. Scientific Reports. 2013;3:3424. ${ }^{63}$ (C) Synthetic route to amino-functionalized MNPs based on a protected metal-organic precursor. Reprinted with permission from Hu H, Zhang C, An L, et al. General protocol for the synthesis of functionalized magnetic nanoparticles for magnetic resonance imaging from protected metal-organic precursors. Chemistry. 2014;20(23):7160-7167. ${ }^{64}$ Copyright (C) 20I4 John Wiley and Sons.

Abbreviation: MNPs, magnetic nanoparticles.

be utilized as effective CAs for enhancing tumor T1weighted MRI.

PEI is another type of polymer which is commonly used for surface modification. For example, Luo et al reported that PEI-coated $\mathrm{Mn}_{3} \mathrm{O}_{4}$ NPs which had been conjugated with fluorescein isothiocyanate (FI), PEGylated FA and PEG monomethyl ether in turn were used for targeted tumor in vivo MRI. ${ }^{59}$ Moreover, these authors believe that the PEI-coated $\mathrm{Mn}_{3} \mathrm{O}_{4}$ NPs can be modified by PEI along with other biomolecules for multimodal biomedical imaging applications. In order to obtain T1 magnetic resonance CAs with higher $r_{1}$ relaxivity for positive MRI of biological systems, Sun and colleagues proposed the construction of hybrid alginate (AG) nanogels loaded with $\mathrm{Mn}_{3} \mathrm{O}_{4}$-PEI nanoparticles. ${ }^{60}$ Additionally, the hybrid AG/PEI- $\mathrm{Mn}_{3} \mathrm{O}_{4}$ with a high $\mathrm{r}_{1}$ relaxation rate of $26.12 \mathrm{mM}^{-1} \mathrm{~s}^{-1}$ at $0.5 \mathrm{~T}$ 
were approximately 19.5 times higher than $\mathrm{PEI}-\mathrm{Mn}_{3} \mathrm{O}_{4}$ NPs. Moreover, the AG/PEI-Mn ${ }_{3} \mathrm{O}_{4}$ NGs had a longer blood circulation time and better tumor MRI performance in vivo than the PEI- $\mathrm{Mn}_{3} \mathrm{O}_{4} \mathrm{NPs}$.

At present, both PEG and PEI modification strategies are relatively mature. However, the PEG-modified strategy creates a thick hydrophobic hydrocarbon coating shell that has the potential to hinder chemical exchange between protons and magnetic ions, resulting in a relatively low $\mathrm{T} 1$ relaxation rate. An alternative strategy is to use small molecules such as sodium citrate (SC) instead of oleic acid or oleylamine on surfaces of hydrophobic nanoparticles. However, the heating conditions required for the reaction may unfortunately result in the oxidation of $\mathrm{Mn}^{2+}$ to $\mathrm{Mn}^{3+}$ ions. Since $\mathrm{Mn}^{3+}$ ions exhibit both lower unpaired electrons and significantly shorter electron relaxation times than $\mathrm{Mn}^{2+}$ ions, they are not sufficient for achieving efficient water proton exchange and reducing $\mathrm{T} 1$ relaxation of MONs. This means it is necessary to find an optimized surface modification scheme to improve the T1 relaxation rate of MONs. Lei and coworkers designed new $\mathrm{Mn}_{3} \mathrm{O}_{4}$ nanocubes (MOC), which they transferred to aqueous media via dopamine derivatives. ${ }^{8}$ The optimized surface endows the MOC a high $r_{1}$ value $\left(11.76 \mathrm{mM}^{-1} \mathrm{~s}^{-1}\right.$ at $\left.0.5 \mathrm{~T}\right)$ and a low $\mathrm{r}_{2} / \mathrm{r}_{1}$ ratio (1.75), avoiding the interference of T2-weighted imaging on T1-weighted imaging. Importantly, a reasonably designed $\mathrm{pH}$-induced charge-switching surface can be charged negatively in the blood and positively at the tumor site. This unique function is able to improve the circulation behavior of the intelligent $\mathrm{T} 1$ CA in the blood and increase the uptake of cancer cells, thus realizing the accurate detection of solid tumors. On this basis, Lee and colleagues systematically studied the effects of various end-capping ligands such as carboxylate, alcohol, mercaptan, and amine with different anchoring groups on the surface functionalization of hollow manganese oxide nanoparticles (HMONs) to enhance $\mathrm{T} 1$ relaxation. ${ }^{61}$ Among all those studied, carboxylate-anchored ligands showed a significant increase in magnetization when capped on the surface of HMONs. In contrast to previous assumptions about the accessibility of surface $\mathrm{Mn}^{2+}$ ions to water molecules, Lee et al suggest that capping-induced magnetization in HMONs is the cause of enhanced relaxation $\left(r_{1}\right)$ values. In addition, in vivo imaging of oleate-terminated HMONs has been demonstrated in the brains of mice.

Guo and colleagues reported a liver T1-weighted MRI CA with good biocompatibility and a high $\mathrm{T} 1$ relaxation rate $\left(r_{1}=11.6 \mathrm{mM}^{-1} \mathrm{~s}^{-1}\right.$ at $\left.3.0 \mathrm{~T}\right)$, while in vivo experiments indicated that the liver signal of mice increased by $50.1 \%$ four hours after injection with the CA. ${ }^{62}$ This CA was synthesized using a two-step process; after dehydration and aromatization under hydrothermal conditions, caramelized carbon nanoparticles (CNPs) were prepared from glucose and utilized as self-sacrificing templates to deposit ultra-thin manganese oxide nanosheets from the redox reaction between $\mathrm{CNP}$ and $\mathrm{KMnO}_{4}$. The afore-mentioned manganese oxide-based nanoprobes were synthesized using a two-step or a multi-step method. In contrast, Xiao et al proposed a one-step method for the preparation of ligand-free $\mathrm{Mn}_{3} \mathrm{O}_{4}$ NPs using liquid laser ablation. ${ }^{63}$ The prepared $\mathrm{Mn}_{3} \mathrm{O}_{4}$ NPs directly interact with water molecules without modification (see Figure 1B). In addition, MTT assay indicated that the cytotoxicity of $\mathrm{Mn}_{3} \mathrm{O}_{4}$ NPs was negligible. Immunotoxicity assessment showed that the $\mathrm{Mn}_{3} \mathrm{O}_{4}$ NPs slightly stimulated the immune response system, but there was no significant difference between $\mathrm{Mn}_{3} \mathrm{O}_{4}$ NPs and commercial MRI CA Gd-DTPA, and the immune response was accepted by the body. Systematic studies of intrinsic toxicity have shown that $\mathrm{Mn}_{3} \mathrm{O}_{4}$ NPs with a high relaxation rate of $8.26 \mathrm{mM}^{-1} \mathrm{~s}^{-1}$ at $3 \mathrm{~T}$ have satisfactory biocompatibility in vitro and in vivo. The T1-weighted MR images showed that the signal of xenograft tumors was enhanced significantly after 30 mins of intravenous injection of $\mathrm{Mn}_{3} \mathrm{O}_{4}$ NPs. Hu and colleagues developed a simple, universal, cost-effective strategy for synthesizing water-soluble and amino-functionalized magnetic nanoparticles through the thermal decomposition of metal-organic precursors protected by phthalimide, followed by deprotection (Figure 1C). ${ }^{64}$ Obtained amino-functionalized $\mathrm{Mn}_{3} \mathrm{O}_{4} \mathrm{NPs}$ have a particle size of $6.6 \mathrm{~nm}$ and a relaxation rate of $2.74 \mathrm{mM}^{-1} \mathrm{~s}^{-1}$, and when further conjugated with FA, these can specifically target cancer cells overexpressing FA receptors.

\section{$\mathrm{Mn}_{3} \mathrm{O}_{4}$ As MR Contrast Agents In Bimodal And Multimodal Imaging}

MRI has the advantages of high spatial resolution and no tissue penetration depth limitation, but its low temporal resolution and low sensitivity characteristics limit its clinical application. The combination of MRI and other modal imaging can provide more adequate functional and anatomical imaging information. In order to meet the challenges of clinical diagnosis, it is necessary to develop an imaging modal combination system that can combine the advantages of single modality. T1 CAs produce a bright signal but has inherently low magnetic resonance relaxation, 
while T2 CAs, especially superparamagnetic iron oxide nanoparticles, have a high detection sensitivity for lesions but are prone to magnetic artifacts and inherent dark imaging features. Therefore, an MR CA that integrates $\mathrm{T} 1$ and $\mathrm{T} 2$ contrast capabilities will enhance the sensitivity and accuracy of magnetic resonance detection. $\mathrm{Li}$ and colleagues first synthesized branched PEI-coated $\mathrm{Fe}_{3} \mathrm{O}_{4} @ \mathrm{Mn}_{3} \mathrm{O}_{4}$ NPs $\left(\mathrm{Fe}_{3} \mathrm{O}_{4} @ \mathrm{Mn}_{3} \mathrm{O}_{4}\right.$-PEI NCs) by using the one-pot hydrothermal method and then modifying hyaluronic acid (HA) on the surface of particles via PEI amine. ${ }^{65}$ The synthesized HA-modified $\mathrm{Fe}_{3} \mathrm{O}_{4} @ \mathrm{Mn}_{3} \mathrm{O}_{4}$ NPs showed a relatively high relaxation of $r_{2}(143.26$ $\left.\mathrm{mM}^{-1} \mathrm{~s}^{-1}\right)$ and $\mathrm{r}_{1}\left(2.15 \mathrm{mM}^{-1} \mathrm{~s}^{-1}\right)$ for targeting $\mathrm{T} 1 / \mathrm{T} 2$ dual-mode magnetic MRI of cancer cells overexpressing the CD44 receptor. CAs reported by Li are "always on" systems that exert MR contrast effects, regardless of whether or not they approach or interact with target cells in the organism, which Kim suggested may lead to a poor target-to-background ratio. ${ }^{66}$ Therefore, Kim and colleagues designed a polysorbate 80 surface-modified redoxresponsive heterostructure (RANs) which was composed of a superparamagnetic $\mathrm{Fe}_{3} \mathrm{O}_{4}$ core and a paramagnetic $\mathrm{Mn}_{3} \mathrm{O}_{4}$ shell as a T1/T2 dual-mode MRI CA. ${ }^{66}$ In aqueous environments, the $\mathrm{Mn}_{3} \mathrm{O}_{4}$ shell protects the $\mathrm{Fe}_{3} \mathrm{O}_{4}$ core from water, resulting in a low CA T2 relaxation property. The $\mathrm{Mn}$ center is also confined to the $\mathrm{Mn}_{3} \mathrm{O}_{4}$ structure, resulting in low water accessibility and magnetic coupling with a superparamagnetic core. The contrast effect between $\mathrm{T} 1$ and $\mathrm{T} 2$ is the OFF state. While tumor cells accumulate CAs through enhanced penetration and retention (EPR) effects, the $\mathrm{Mn}_{3} \mathrm{O}_{4}$ shell reacts with abundant GSH in the cytoplasm to dissolve into $\mathrm{Mn}^{2+}$ ions. A great many high-spin $\mathrm{Mn}^{2+}$ ions and exposed $\mathrm{Fe}_{3} \mathrm{O}_{4}$ cores can be used as CAs for T1- and T2- MR, respectively. Redox activation produces a significant enhancement of $\mathrm{T} 1$ and T2 signal contrast (ON state). In addition, Kim and colleagues performed T1- and T2-weighted MR imaging in tumor-bearing mice using effective passive tumor targeting, demonstrating that these complexes can be utilized as dual-mode magnetic resonance CAs (see Figure 2A).

Due to the high sensitivity of PET as well as the ultra-high spatial resolution and good soft tissue contrast of MRI, PET, and MRI dual-mode imaging can be currently used for clinical cancer detection, while the development of PET/T1-MRI bimodal mode probes best meets clinical demands. Zhu and colleagues synthesized PEI-coated $\mathrm{Mn}_{3} \mathrm{O}_{4}$ NPs through the solvothermal decomposition of acetylacetone manganese. ${ }^{67}$ PET/MRI bimodal probes were constructed using FA modification and ${ }^{64} \mathrm{Cu}$ labeling on the surface of the amine groups $\mathrm{Mn}_{3} \mathrm{O}_{4}$ NPs. The obtained nanoprobes were successfully applied to PET/MRI imaging in small animals; compared with HeLa tumors blocked by folate receptors (FR), ${ }^{64} \mathrm{Cu}$-labeled $\mathrm{Mn}_{3} \mathrm{O}_{4}$ NPs showed a better tracer in HeLa tumors expressing FR $18 \mathrm{hrs}$ after injection. In addition, FR-targeted $\mathrm{Mn}_{3} \mathrm{O}_{4}$ NPs showed accurate tumor T1weighted MRI $18 \mathrm{hrs}$ after injection. Zhan and team also studied PET/MRI dual-mode probes. They constructed ${ }^{64} \mathrm{Cu}-$ labeled, antibody (TRC105)-modified $\mathrm{Mn}_{3} \mathrm{O}_{4}$ NPs for tumor vasculature targeted PET/MRI imaging (see Figure 2B and C). ${ }^{5}$ The anti-CD105 antibody TRC105 was the targeting ligand. CD105 has been shown to be overexpressed in many proliferating tumor endothelial cells, making it applicable for tumor diagnosis and meaning it has the potential to be used as a treatment via the use of nanomaterial. ${ }^{68}$ In vitro, in vivo and ex vivo experiments found good radioactivity and high specificity for the vascular marker CD105 of the $\mathrm{Mn}_{3} \mathrm{O}_{4}$ conjugated NPs $\quad\left({ }^{64} \mathrm{Cu}-\mathrm{NOTA}-\mathrm{Mn}_{3} \mathrm{O}_{4} @\right.$ PEG-TRC105). ${ }^{5}$ According to T1-enhanced imaging as well as in vivo toxicity studies of the $\mathrm{Mn}_{3} \mathrm{O}_{4}$-conjugated NPs, Zhan et al believed that $\mathrm{Mn}_{3} \mathrm{O}_{4}$ NPs can be used as a safe nanoplatform for long-term targeted tumor imaging, diagnosis, and even treatment. Based on this, these authors also proposed chelator-free zirconium-89 $\left({ }^{89} \mathrm{Zr}, \mathrm{t}_{1 / 2}: 78.4 \mathrm{hrs}\right)$ labeled $\mathrm{Mn}_{3} \mathrm{O}_{4}$ NPs ([ $\left.{ }^{89} \mathrm{Zr}\right] \mathrm{Mn}_{3} \mathrm{O}_{4} @$ @EG) for in vivo PET/MRI imaging and lymph node mapping. ${ }^{69}$ Before that, Zhan and colleagues developed an optical/MRI dual-mode imaging probe for in vivo bimodal imaging to guide lymph node mapping (see Figure $2 \mathrm{D}$ and E). ${ }^{70}$ They constructed a hybrid optical/MRI system based on PEG-coated $\mathrm{Mn}_{3} \mathrm{O}_{4}$ NPs conjugated Cy7.5. The obtained $\mathrm{Mn}_{3} \mathrm{O}_{4} @$ PEG-Cy7.5 exhibited good colloidal stability as well as good biocompatibility.

\section{$\mathrm{Mn}_{3} \mathrm{O}_{4}$ As MR Contrast Agents In Imaging-Guided Tumor Therapy}

Cancer is a serious threat to human life and health, and the development of the theragnostics methods is seen by researchers as having great importance. Theragnostics is a burgeoning field in medical research which allows for simultaneous diagnostic and specific therapy to enhance overall patient treatment and safety. ${ }^{71}$ As illustrated in Figure 3, numerous research groups have used a variety of nanotechnology approaches to contribute to the development of theragnostic agents. Wang and colleagues demonstrated that $\mathrm{Mn}_{3} \mathrm{O}_{4}$ NPs have been dissociated in response to the redox reaction with $\mathrm{GSH}$ in an intracellular reducing 

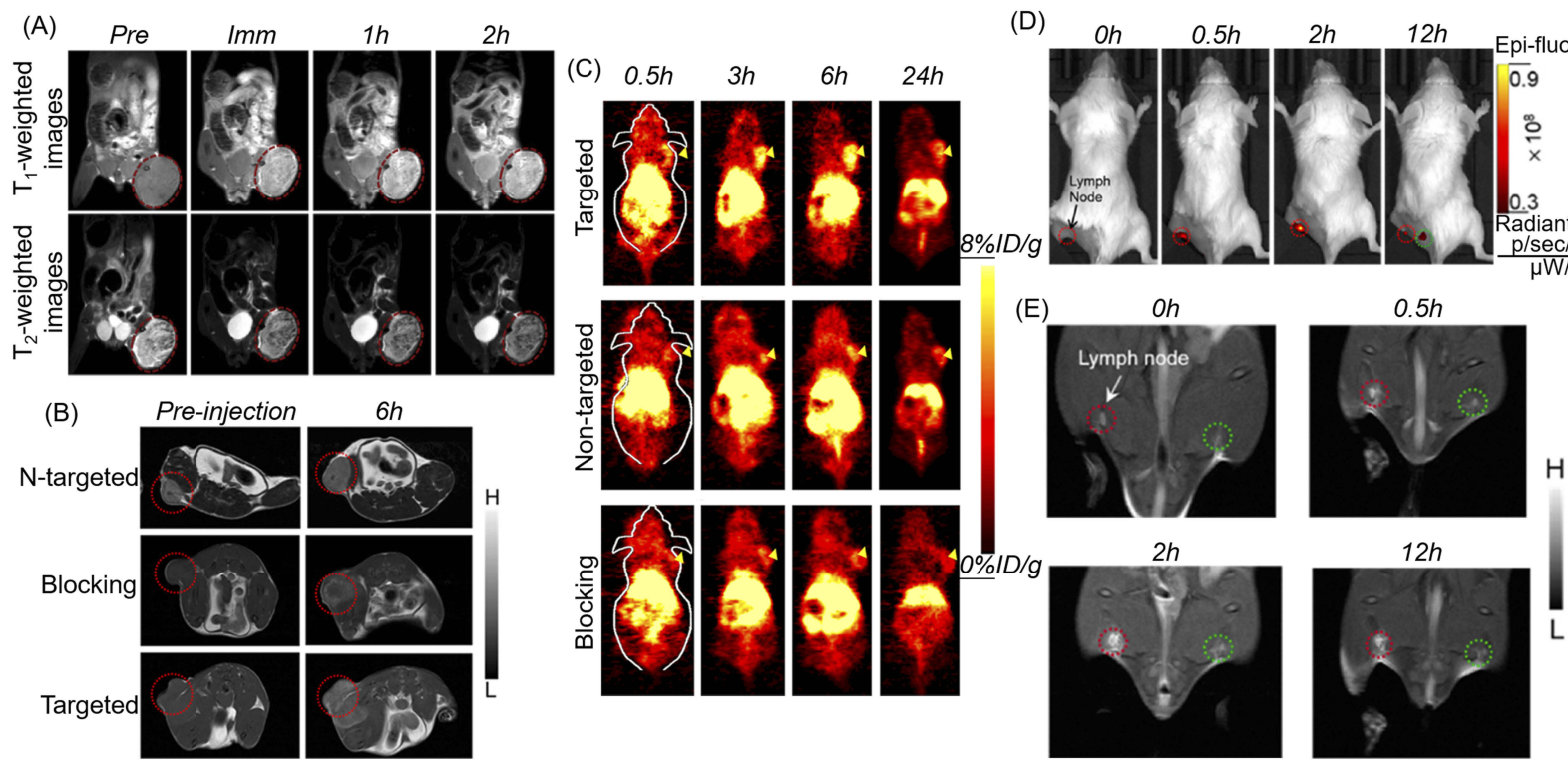

Figure 2 (A) TI- and T2-weighted MR imaging of tumors with $\mathrm{Fe}_{3} \mathrm{O}_{4} @ \mathrm{Mn}_{3} \mathrm{O}_{4}$ NPs. Reprinted from Kim MH, Son HY, Kim GY, Park K, Huh YM, Haam S. Redoxable heteronanocrystals functioning magnetic relaxation switch for activatable $\mathrm{TI}$ and T2 dual-mode magnetic resonance imaging. Biomaterials. 20I6; I0I:I2I-I30 ${ }^{66}$ Copyright $\odot$ 2016, with permission from Elsevier. Serial coronal TI-MRI imaging (B) and PET images (C) of 4TI tumor-bearing mice after injection of ${ }^{64} \mathrm{Cu}-\mathrm{NOTA}-\mathrm{Mn}{ }_{3} \mathrm{O}_{4} @ P E G-$ TRCI05, ${ }^{64} \mathrm{Cu}-\mathrm{NOTA}-\mathrm{Mn}_{3} \mathrm{O}_{4} @$ QPEG, or ${ }^{64} \mathrm{Cu}-\mathrm{NOTA}-\mathrm{Mn}_{3} \mathrm{O}_{4} @$ @EG-TRCI05 after a preinjected blocking dose of TRCI05. Reproduced from Zhan Y, Shi S, Ehlerding EB, et al. Radiolabeled, Antibody-Conjugated Manganese Oxide Nanoparticles for Tumor Vasculature Targeted Positron Emission Tomography and Magnetic Resonance Imaging. ACS Appl Mater Interfaces. 2017;9(44):38304-383I2. ${ }^{132}$ Copyright (C) 2017 American Chemical Society. In vivo fluorescence imaging (D) and TI-MR imaging (E) of lymph nodes with Mn3O4@PEG-Cy7.5 NPs in BALB/c mice at different post-injection time points. Reprinted from Zhan Y, Zhan W, Li H, et al. In Vivo Dual-Modality Fluorescence and Magnetic Resonance Imaging-Guided Lymph Node Mapping with Good Biocompatibility Manganese Oxide Nanoparticles. Molecules. 20I7;22(I2):2208. ${ }^{70}$

Abbreviations: Pre, pre-injection; Imm, immediate; N-targeted, non-targeted.

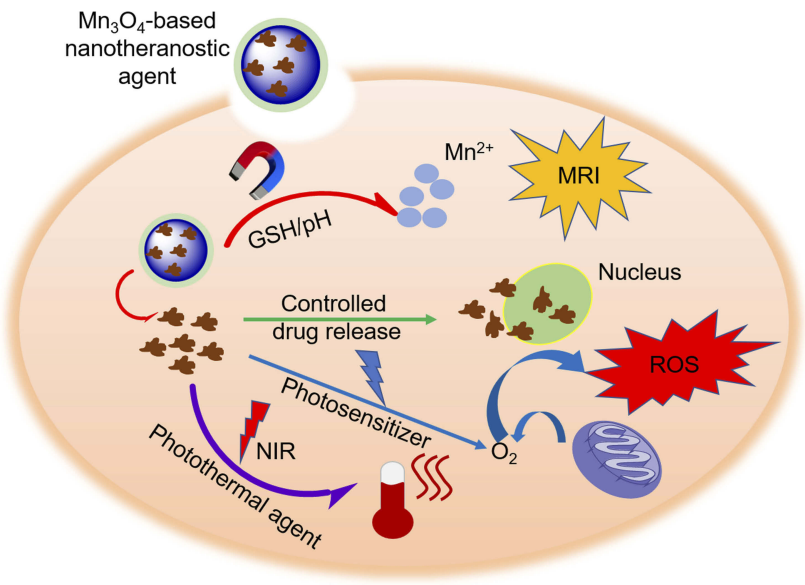

Figure 3 The mechanism of $\mathrm{Mn}_{3} \mathrm{O}_{4}$-based nanotheranostic agents for imagingguided chemotherapy/PDT/PTT and tumor MR imaging.

Abbreviations: NIR, near-infrared; ROS, reactive oxygen species; PDT, photodynamic therapy.

environment. ${ }^{72}$ Based on this, they constructed a multifunctional mesoporous silica-based redox-mediated nanotheranostic system using $\mathrm{Mn}_{3} \mathrm{O}_{4}$ nanolids. The assembly process for this nanotheranostic system is as follows: firstly, mesoporous silica nanoparticles (MSN) were prepared via sol-gel chemistry. MSN were then surface functionalized using carboxylic groups to ensure the loading of camptothecin (CPT) to nanochannels; finally, hydrothermally synthesized $\mathrm{Mn}_{3} \mathrm{O}_{4}$ NPs were treated using 3-aminopropyltriethoxysilane (APTES) and obtained $\mathrm{Mn}_{3} \mathrm{O}_{4}-\mathrm{NH}_{2}$ nanolids were capped to MSN-COOH structure loaded with CPT to avoid premature release of cytotoxic drugs. The $r_{1}$ value of the system was calculated to be $13.39 \mathrm{mM}^{-1} \mathrm{~s}^{-1}$ at $3.0 \mathrm{~T}$. Exposure of the nanotheranostic system, drug-loaded $\mathrm{Mn}_{3} \mathrm{O}_{4} @ \mathrm{MSN}$, to an intracellular GSH environment results in the dissolution of $\mathrm{Mn}_{3} \mathrm{O}_{4}$ nanolids and the intelligent release of drugs. In addition, the redox reaction dissociates the paramagnetic $\mathrm{Mn}_{3} \mathrm{O}_{4}$ NPs to $\mathrm{Mn}^{2+}$, which doubles the T1 signal $\left(\mathrm{r}_{1}=25.17\right.$ $\mathrm{mM}^{-1} \mathrm{~s}^{-1}$ ) and provides an additional opportunity to track therapeutic feedback. Zhang and co-workers designed an intelligent system for imaging diagnostics and chemotherapeutic applications. ${ }^{73}$ The highly integrated nanocomposite Dox- $\mathrm{Mn}_{3} \mathrm{O}_{4}$-SiNTs was assembled by uniformly distributing $\mathrm{Mn}_{3} \mathrm{O}_{4}$ NPs within mesoporous silicon nanotubes (SiNTs, 10-20 nm), while Dox was loaded into the mesoporous wall $(\sim 5 \mathrm{~nm})$ of SiNTs. A series of in vitro and in vivo studies revealed that the Dox- $\mathrm{Mn}_{3} \mathrm{O}_{4}$-SiNTs nanotheranostic system has an excellent T1-weighted MRI performance $\left(\mathrm{r}_{1}=1.72\right.$ $\mathrm{mM}^{-1} \mathrm{~s}^{-1}$ at $3.0 \mathrm{~T}$ ), which demonstrated a $\mathrm{pH}$-dependent release behavior and exhibited remarkable therapeutic effects against both HeLa cells and cervical cancer xenografts. 
Photodynamic therapy (PDT) is an efficient clinical therapy in which cancer cells are damaged by reactive oxygen species produced by non-toxic photosensitizers which have been exposed to specific wavelengths. ${ }^{74}$ Imaging-guided PDT can provide more accurate tumor localization and reduce side effects on typical tissue. Nafiujjaman and colleagues developed a ternary hybrid probe, saved as dual imaging-guided PDT agent, which consisted of $\mathrm{Mn}_{3} \mathrm{O}_{4}$ and graphene quantum dots (GQD) linked by PDA and thiol-amine. ${ }^{75}$ Several stability studies of the hybrid system (GQD-PDA- $\mathrm{Mn}_{3} \mathrm{O}_{4}$ ) have indicated that the link between $\mathrm{Mn}_{3} \mathrm{O}_{4}$ and GQD can be maintained in different conditions, although partial fluorescence quenching occurs in GQD thanks to the presence of $\mathrm{Mn}_{3} \mathrm{O}_{4}$. While these nanoparticles exhibit good biocompatibility in dark conditions, subsequent laser irradiation can trigger GQD to generate effective fluorescent emissions and reactive oxygen species, killing cancer cells and leading tumor regression. Meanwhile, GQD-PDA- $\mathrm{Mn}_{3} \mathrm{O}_{4}$ nanoparticles also exhibited excellent optical and T1weighted MRI capability. Ding and colleagues designed a multifunctional FA conjugated, drug (Dox)-loaded $\mathrm{Mn}_{3} \mathrm{O}_{4} @$ PDA@PEG nanotheranostic agent to be utilized for MRI-guided synergetic chemo-/photothermal (PTT) therapy. ${ }^{76}$ The nanotheranostic agent with an ultrahigh T1-relaxivity of $14.47 \mathrm{mM}^{-1} \mathrm{~s}^{-1}$ at $1.2 \mathrm{~T}$ demonstrated excellent MRI ability in vitro and in vivo as well as providing overall information for tumor diagnosis and therapeutic effect monitoring. PDA can not only endow the nanotheranostics system with biocompatibility but can also act as a photothermal conversion agent for PTT and an anti-cancer drug carrier. NIR When the $808 \mathrm{~nm}$ nearinfrared laser irradiation drug release was triggered, the nanotheranostics agent showed a significantly enhanced tumor synergistic effect, compared with both PTT and chemotherapy alone. Additionally, following the development of nanotheranostic agents, the nanotoxicity of agents has been challenged. Liu et al have developed an artificially induced degradation of ethylenediaminetetraacetic calcium disodium salt (EDTA)- and bovine serum albumin (BSA)-capped $\mathrm{Mn}_{3} \mathrm{O}_{4}$ NPs (MONPs-BSA-EDTA) as a novel, inorganic nanomaterial for T1/T2-MRI guided PTT. $^{77}$ Due to the high electron spin and strong NIR absorption, $\mathrm{Mn}_{3} \mathrm{O}_{4}$ NPs not only act as a T1-T2 dualmode MR contrast agent but also as a photothermal conversion agent. MONPs were degraded into free ultra-small $\mathrm{Mn}_{3} \mathrm{O}_{4}$ NPs and $\mathrm{Mn}^{2+}$ with the introduction of ascorbic acid. Moreover, $\mathrm{Mn}^{2+}$, which is considered toxic to the living system, can be captured by BSA coating on the particles and EDTA loaded thereon, thereby avoiding the nanotoxicity of the inorganic nanomaterial.

\section{$\mathrm{MnO}_{2}$-Based Nanoparticles In Tumor Diagnosis And Therapy}

It is well known that the growth and metabolism of tumor cells are not strictly regulated in the way that they are in typical cells, which results in the microenvironment of tumor tissues being rather different from typical tissues. On one hand, $\mathrm{H}_{2} \mathrm{O}_{2}$ is overproduced in malignant tumor cells and thus results in a significant increase in the level of $\mathrm{H}_{2} \mathrm{O}_{2}$ in a TME. ${ }^{78}$ On the other hand, upregulated glycolysis metabolism during tumorigenesis produces a large amount of lactic acid, resulting in a low $\mathrm{pH}$ value of TME. ${ }^{79}$ It has additionally been reported that GSH in tumor tissues is almost five times that of typical tissues and that GSH plays a key role in protecting cells from various harmful substances such as $\mathrm{H}_{2} \mathrm{O}_{2}$, superoxide, hydroxyl radical, and other reactive oxygen species. ${ }^{80}$ Hypoxia is a prominent feature of solid tumors which is often associated with tumor invasion, metastasis, and resistance to traditional therapies. ${ }^{81}$ This means that the high GSH levels and hypoxia characteristics of cancer cells have been shown to increase resistance to chemotherapy, radiotherapy, and photodynamic therapy (PDT). As reported, manganese dioxide $\left(\mathrm{MnO}_{2}\right)$ has the ability to react with GSH to reduce $\mathrm{Mn}^{4+}$ to $\mathrm{Mn}^{2+}$. While consuming intracellular $\mathrm{GSH}$, the $\mathrm{Mn}^{2+}$ produced can not only enhance T1-MRI but also undergoes a Fenton reaction with $\mathrm{H}_{2} \mathrm{O}_{2}$ to form a hydroxyl radical $(\cdot \mathrm{OH})$, the most harmful reactive oxygen species (ROS). ${ }^{80}$ Therefore, in recent years, research on manganese dioxide nanoparticles $\left(\mathrm{MnO}_{2} \mathrm{NPs}\right)$ has ignited, owing to these nanoparticles' excellent T1-weighted MRI capability and ability to respond intelligently to TME as a nanotheranostic agent.

\section{$\mathrm{MnO}_{2}$ As Contrast Agents In MRI And Cellular GSH Detection}

MRI plays a key role in clinical detection, especially soft tissue. Traditional magnetic resonance CAs tend to be "always on" regardless of whether they are close to or interact with the target cell, which may result in a poor signal-to-noise ratio. Recently, studies have found that $\mathrm{MnO}_{2}$ can enhance the contrast of magnetic resonance signals in response to endogenous stimuli such as $\mathrm{pH}$, GSH (see Figure 4A). Based on this, many researchers 
(A)

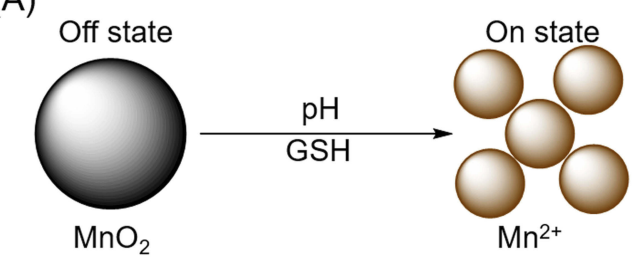

(B)
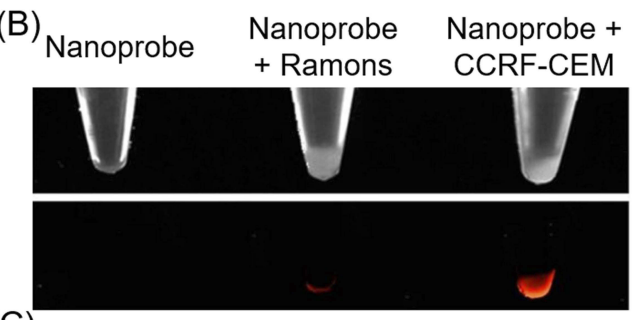

(C)

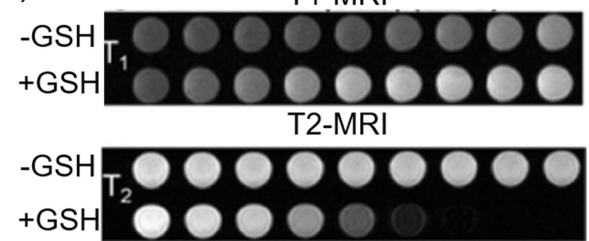

(D) Tumor-bearing NEM-pretreated
mouse tumor-bearing Pre-injection $\mathrm{Ru}(\mathrm{BPY})_{3} @ \mathrm{MnO}_{2}$ -injected
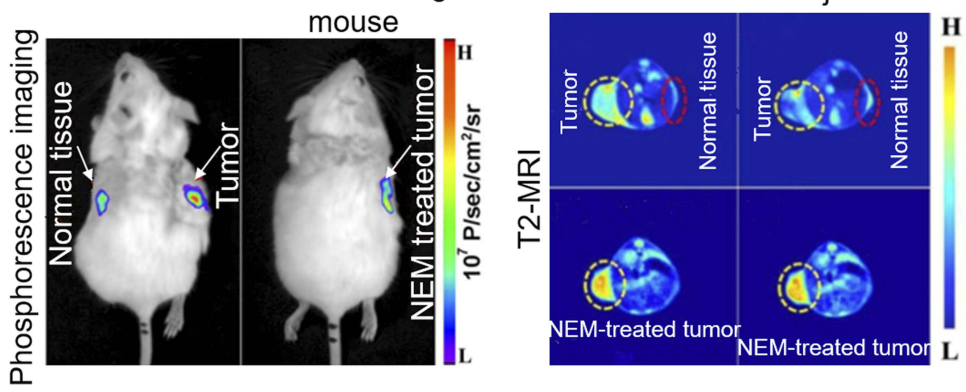

(E)
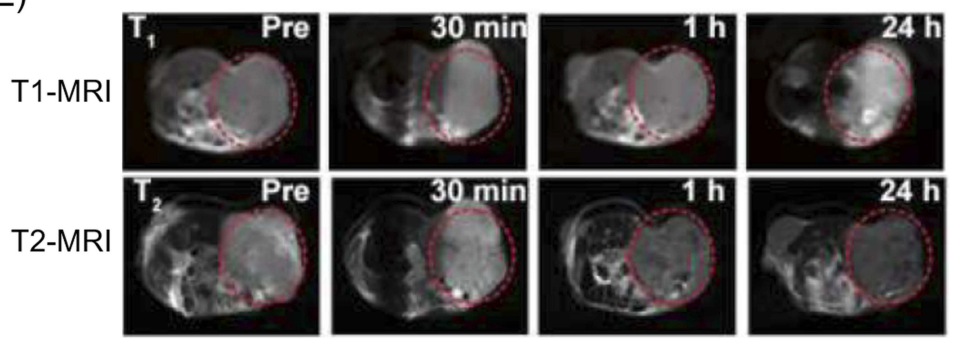

Figure 4 (A) Schematic that $\mathrm{MnO}_{2} \mathrm{NPs}$ enhance the magnetic resonance contrast under endogenous stimulation. (B) Optical (above) and fluorescent images (below) of $\mathrm{MnO}_{2}$ nanosheet-sgc8 nanoprobe to target cells. (C) TI- and T2-weighted MRI of $\mathrm{MnO}_{2}$ nanosheet solution treated with GSH. Reproduced with permission from Zhao ZL,

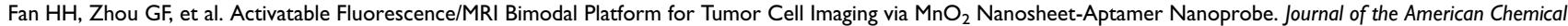
Society. 2014;136(32): I 1220-1 1223. ${ }^{82}$ Copyright (C) 2014 American Chemical Society. (D) Phosphorescence images and T2-weighted MR images of a tumor-bearing mouse and a NEM-pretreated tumor-bearing mouse after injected with Ru(BPY) ${ }_{3} @ M_{n} \mathrm{O}_{2}$ for 15 mins. Reproduced from Shi W, Song B, Shi W, et al. Bimodal PhosphorescenceMagnetic Resonance Imaging Nanoprobes for Glutathione Based on $\mathrm{MnO}_{2}$ Nanosheet-Ru(II) Complex Nanoarchitecture. ACS Appl Mater Interfaces. 20I8; I0(33):2768I$27691 .{ }^{83}$ Copyright @ 2018 American Chemical Society. (E) TI- and T2-MRI of tumors with Fe $\mathrm{O}_{4} @ \mathrm{C}_{0} @ \mathrm{MnO}_{2} \mathrm{NPs}$. Reproduced from Duan B, Wang D, Wu H, et al. CoreShell Structurized $\mathrm{Fe}_{3} \mathrm{O}_{4} @ \mathrm{C} @ \mathrm{MnO}_{2}$ Nanoparticles as $\mathrm{pH}$ Responsive TI-T2* Dual-Modal Contrast Agents for Tumor Diagnosis. ACS Biomaterials Science \& Engineering. 2018;4(8):3047-3054. ${ }^{84}$ Copyright (C) 2018 American Chemical Society.

Abbreviation: NEM, N-ethylmaleimide.

have made deliberate achievements in the activatable magnetic resonance $\mathrm{CAs}$ of $\mathrm{MnO}_{2}$. Zhao and colleagues reported a dual-activatable fluorescence/MRI bimodal nanoprobe which was based on $\mathrm{MnO}_{2}$ nanosheet-Cy5 labeled aptamer nanoparticles for tumor cell imaging. ${ }^{82}$ In this dual-mode imaging system, $\mathrm{MnO}_{2}$ nanosheets act as a nanocarrier to deliver aptamer, a fluorescence quencher, as well as an intracellular GSH-activated T1/ T2-MRI CA (see Figure 4C). When the aptamer does not target cells, neither the fluorescence signals nor the MRI contrast of nanoprobes were activated. Conversely, once the target cells exist, the binding of aptamers to their targets will lead to a decrease in the adsorption of aptamers on $\mathrm{MnO}_{2}$ nanosheets, resulting in partial fluorescence recovery (see Figure 4B), irradiation of target cell, and the promotion of endocytosis of nanoprobes to the target cell. Following endocytosis, GSH reduced $\mathrm{MnO}_{2}$ nanosheets to further activate the fluorescent signal and produce many $\mathrm{Mn}^{2+}$ ions suitable for MRI. Moreover, the reduced $\mathrm{Mn}^{2+}$ ions exhibited both 48 -fold and 120 -fold enhancements in the longitudinal relaxation rate $r_{1}$ and the transverse relaxation rate $r_{2}$ when compared to the $\mathrm{MnO}_{2}$ nanosheets. This platform promotes the development of various activatable fluorescent/MRI bimodal imaging for cells.

For clinical diagnosis, in vitro evaluation of nanoprobes is not sufficient. Based on this, Shi and colleagues reported a GSH-activated $\mathrm{Ru}(\mathrm{BPY})_{3} @ \mathrm{MnO}_{2}$ bimodule phosphorescence/MR imaging nanoprobe for the determination of GSH in vitro and in vivo (see Figure 4D). ${ }^{83}$ As previously described, $\mathrm{MnO}_{2}$ nanosheets are both phosphorescent quenchers and GSH-responsive MR CAs. After being triggered by $\mathrm{GSH}, \mathrm{MnO}_{2}$ nanosheets can be rapidly reduced to $\mathrm{Mn}^{2+}$ ions, which leads to enhancement of the T1- and T2weighted MR signals ( $r_{1}$ increased from 0.11 to 9.33 $\mathrm{mM}^{-1} \mathrm{~s}^{-1}$, and $\mathrm{r}_{2}$ increased from 0.16 to $48.77 \mathrm{mM}^{-1} \mathrm{~s}^{-1}$ at $0.5 \mathrm{~T}$ ) while recovering the phosphorescence of the $\mathrm{Ru}(\mathrm{II})$ complex. Since the enhancement factor of $r_{2}$ ( 85 folds) is 2.6 times higher than that of $\mathrm{r}_{1}$ (305 folds), this means that when $\mathrm{Ru}(\mathrm{BPY})_{3} @ \mathrm{MnO}_{2} \mathrm{NPs}$ are used as T2-MR contrast agents, a higher signal-to-noise ratio can be obtained. The GSH concentration can be quantified by phosphorescence and MR. The time-gated luminescence (TGL) assay of GSH in human 
serum as well as the visualization of endogenous GSH in zebrafish and tumor-bearing mice in both phosphorescence and MR imaging modes confirmed that the prepared nanoprobes have good biocompatibility and fast response as well as a high sensitivity and selectivity to GSH. Moreover, Duan and colleagues constructed a core-shell $\mathrm{Fe}_{3} \mathrm{O}_{4} @ \mathrm{C} @ \mathrm{MnO}_{2}$ nanoprobe via an in situ self-reduction method which was used as a pH-responsive T1-T2* dual-modal MRI contrast agent (Figure 4E). ${ }^{84}$ The release rate of $\mathrm{Mn}^{2+}$ ions in acidic PBS with $\mathrm{pH}$ of 5.0 is approximately 10 times that of $\mathrm{pH} 7.4$, which promotes the release of synthesized nanoparticles in the acidic environment of tumors. Following intravenous injection of $\mathrm{Fe}_{3} \mathrm{O}_{4} @ \mathrm{C} @ \mathrm{MnO}_{2} \mathrm{NPs}$ for 24 hours, the T1 MRI signal in the tumor area was significantly enhanced by $127 \%$ compared with prior to injection. At the same time, the T2 MRI signal was weakened to $71 \%$. Therefore, the $\mathrm{Fe}_{3} \mathrm{O}_{4} @ \mathrm{C} @ \mathrm{MnO}_{2}$ NPs are able to significantly increase the accuracy of the diagnosis and can be expected to develop as a clinical, multi-diagnostic nanoplatform.

\section{$\mathrm{MnO}_{2}$ As MR Contrast Agents In Imaging-Guided Tumor Therapy} $\mathrm{MnO}_{2}$ NPs For Enhanced Chemotherapy And MRI

Chemotherapy is a traditional cancer treatment which damages healthy cells while killing cancer cells. It has many side effects. Moreover, hypoxia, a major characteristic of most solid tumors, not only promotes the invasiveness and metastasis of malignant cells but is also associated with resistance to radiation and chemotherapy. ${ }^{85}$ This means that a major challenge for enhancing the therapeutic effects and minimizing the side effects of chemotherapy is the need to achieve on-demand drug release and alleviate tumor hypoxia. As previously reported, $\mathrm{MnO}_{2}$ nanoparticles have received extensive researcher attention due to their high reactivity to hydrogen peroxide for producing $\mathrm{O}_{2}$ and their response to $\mathrm{pH}$ decomposition into $\mathrm{Mn}^{2+}$, which can be used as MR CAs.

Many researchers have made significant contributions to the construction of $\mathrm{MnO}_{2}$-based smart drug delivery systems (see Table 2). ${ }^{51,80,86-95}$ Among these, Song and colleagues reported on Dox loading, HA-modified and mannan conjugated $\mathrm{MnO}_{2}$ nanoparticles (Man-HA-MnO $2 \mathrm{NPs}$ ) for targeting 4T1 mouse breast cancer cell imaging and enhancing chemotherapy. ${ }^{87}$ The high accumulation of tumor-associated macrophages (TAMs) in hypoxic regions of solid tumor as well as the high reactivity of $\mathrm{MnO}_{2} \mathrm{NPs}$ toward $\mathrm{H}_{2} \mathrm{O}_{2}$ led to simultaneous generation of $\mathrm{O}_{2}$ and the regulation of $\mathrm{pH}$ to effectively mitigate tumor hypoxia. In addition, HA not only serves as a target but can also reprogram anti-inflammatory, pro-tumor M2 TAM into pro-inflammatory, anti-tumor M1 macrophages to further enhance the resultant nanoparticles to reduce tumor hypoxia and regulate chemoresistance. At the same time, $\mathrm{Mn}^{2+}$ ions released by the reaction of Man-HA- $\mathrm{MnO}_{2} \mathrm{NPs}$ with $\mathrm{H}_{2} \mathrm{O}_{2}$ significantly enhanced both the tumor imaging and the detection performance of T1 and T2-MRI. Inspired by the biological process of $\mathrm{KMnO}_{4}$ disinfection, Pan et al prepared a multifunctional $\mathrm{BSA}-\mathrm{MnO}_{2}$ nanoplatform which had a uniform size of less than $10 \mathrm{~nm}$, excellent colloid stability, and high $\mathrm{T} 1$ relaxation rate of $7.9 \mathrm{mM}^{-1} \mathrm{~s}^{-1}$ at 0.5 T by drug-substrate interaction strategy. ${ }^{90}$ The BSA-MnO nanoprobe can not only be used as a high-performance MRI agent for tumor and renal imaging but also as a MRI-guided photothermal and chemotherapeutic agent when loaded with indocyanine green and paclitaxel, respectively. Pan's work provides a new method for the development of therapeutic agents. In Zhang's study, $\mathrm{MnO}_{2} /$ Dox-loaded albumin nanoparticles (BMDN) were fabricated as a theragnostic agent for cancer MRI and a reversing multidrug resistance (MDR) tumor chemotherapy. ${ }^{91}$ MDR hinders the effects of chemotherapy. At present, nanocarriers are a potential means for overcoming tumor MDR, ${ }^{96}$ while albumin has been extensively studied as a hopeful drug carrier for nanocarrier construction due to both its excellent biocompatibility and low immunogenicity. Additionally, albumin can promote the delivery of BMDN to tumor cells, enhance cellular uptake, achieve on-demand drug release, and reduce tumor hypoxia through interaction with albumin receptors overexpressed on cancer cells. The weak acidic response of BMDN promotes the release of $\mathrm{Mn}^{2+}$, resulting in enhanced T1-weighted imaging both in vitro and in vivo.

In order to achieve simultaneous accurate diagnosis and effective treatment of hypoxic tumors, Song and colleagues designed and synthesized a versatile rattle-structure nanotheranostic agent, with an up-conversion nanoparticle (UCNP) as the core wrapped in hollow mesoporous silica, Dox loaded in the cavity, a hypoxia-sensitive $\mathrm{MnO}_{2}$ nanosheet enriched on the mesopores, as well as PEG and DOTA ligands conjugated onto the outer surface of the nanoparticles. ${ }^{95} \mathrm{MnO}_{2}$ nanosheets can be degraded to $\mathrm{Mn}^{2+}$ ions in various acidic TME caused by varying degrees of hypoxia, while the resulting $\mathrm{Mn}^{2+}$ ions can be captured by DOTA for real-time T1-MRI diagnosis of hypoxic tumors. In addition, the nanoplatform can on-demand release Dox and supplement $\mathrm{O}_{2}$ to result in both normoxiaand hypoxia-sensitive chemotherapy with a single drug. 


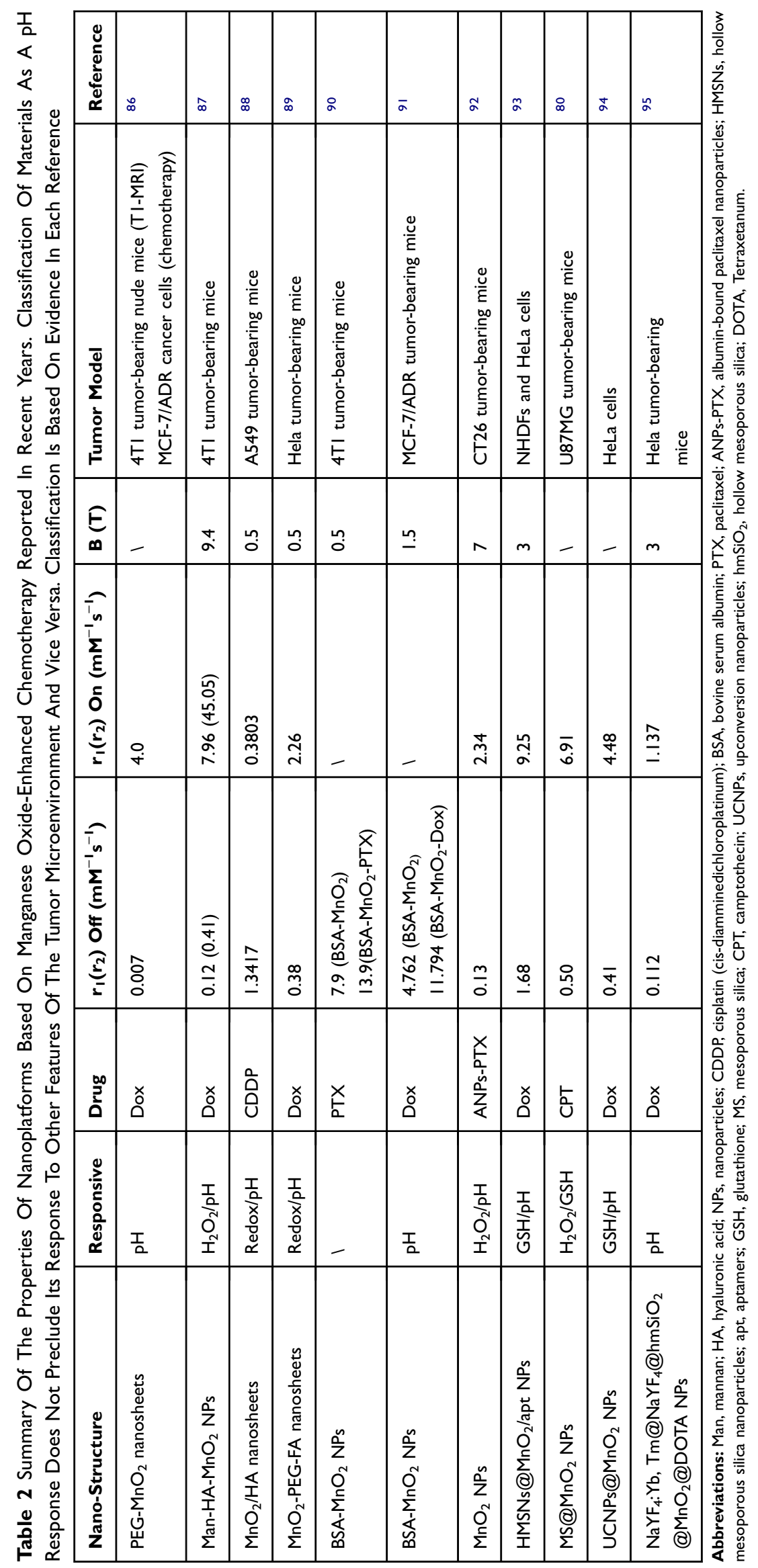


Recently, efforts have been made to develop ROS-based cancer therapeutic strategies, particularly chemodynamic therapy (CDT) which uses iron-mediated Fenton reactions. ${ }^{97}$ Unfortunately, overexpressed GSH in cancer cells has the ability to clear $\cdot \mathrm{OH}$, which greatly reduces $\mathrm{CDT}$ efficacy. Based on this, Lin et al were the first to report a self-reinforced CDT nanomaterial based on $\mathrm{MnO}_{2}$, which proposes Fenton-like $\mathrm{Mn}^{2+}$ delivery capacity as well as GSH depletion characteristics. ${ }^{51}$ These authors synthesized camptothecinloaded, $\mathrm{MnO}_{2}$-coated mesoporous silica NPs (MS@ $\mathrm{MnO}_{2}$ CPT) for MRI-monitored chemo-chemodynamic synergistic cancer treatment. Once cancer cells take up the $\mathrm{MS} @ \mathrm{MnO}_{2^{-}}$ CPT NPs, the $\mathrm{MnO}_{2}$ shell reacts with GSH to reduce $\mathrm{Mn}^{4+}$ ions to $\mathrm{Mn}^{2+}$ ions. While consuming endogenous GSH in the physiological medium rich in $\mathrm{HCO}_{3}{ }^{-}$, the produced $\mathrm{Mn}^{2+}$ not only enhances T1-MRI but also undergoes a Fenton reaction with $\mathrm{H}_{2} \mathrm{O}_{2}$ to form $\cdot \mathrm{OH}$ and so enhance $\mathrm{CDT}$.

\section{$\mathrm{MnO}_{2} \mathrm{NPs}$ For Enhanced Photodynamic Therapy And $\mathrm{MRI}$}

PDT is a non-invasive tumor replacement therapy in which a photosensitizer reacts with the surrounding oxygen to generate a highly active singlet oxygen and so attack internal biomolecules (such as DNA and biological membrane) under laser irradiation at a specific wavelength, resulting in damage to or death of cells. ${ }^{74}$ Unfortunately, the hypoxic environment of tumors ${ }^{98}$ along with the ability of overexpressed GSH to scavenge $\operatorname{ROS}^{80}$ and the short diffusion length of lasers ${ }^{99}$ are all obstacles to the clinical application of PDT. As a result of its typical physicochemical properties, the emerging twodimension $\mathrm{MnO}_{2}$ nanosheets have been studied extensively in enhanced PDT. Crucially, based on the fact that $\mathrm{MnO}_{2}$ nanosheets can react with intracellular GSH to reduce the amount of GSH, Meng and colleagues designed and synthesized an aptamer-conjugated, Dox and Chlorin e6 (Ce6)loaded, $\mathrm{MnO}_{2}$ nanosheets gated, two-photon dye-doped mesoporous silica nanoparticle for GSH-responsive fluorescence/ MR bimodal cellular imaging as well as targeted chemotherapy and PDT. ${ }^{100}$ Additionally, in acidic and $\mathrm{H}_{2} \mathrm{O}_{2}$-rich tumor microenvironments, $\mathrm{MnO}_{2}$ nanosheets can be reduced to $\mathrm{Mn}^{2+}$ while $\mathrm{O}_{2}$ can be formed by the following formula, thus reducing hypoxia in the tumor site: ${ }^{101}$

$$
\begin{gathered}
\mathrm{MnO}_{2}+2 \mathrm{H}^{+} \longrightarrow \mathrm{Mn}^{2+}+\mathrm{H}_{2} \mathrm{O}+1 / 2 \mathrm{O}_{2} \\
\mathrm{MnO}_{2}+\mathrm{H}_{2} \mathrm{O}_{2}+2 \mathrm{H}^{+} \longrightarrow \mathrm{Mn}^{2+}+2 \mathrm{H}_{2} \mathrm{O}+\mathrm{O}_{2}
\end{gathered}
$$

Many researchers have made achievements in this area. Sun and colleagues constructed a smart $\mathrm{pH} / \mathrm{H}_{2} \mathrm{O}_{2-}$ responsive nanoplatform to be utilized for self-enhanced upconversion luminescence/MR/CT-guiding diagnosis and PDT treatment. ${ }^{102}$ This was based on a core-shell-shell structure of Ce6-sensitized up-converted nanoparticleloaded honeycomb manganese oxide $\left(\mathrm{hMnO}_{2}\right)$ nanospheres. Liu et al synthesized BSA-stabilized $\mathrm{MnO}_{2}$ nanostructures (BMnNSs), after which the photosensitizer 2-devinyl-2-(1-hexyloxyethyl) pyropheophorbide (HPPH) was conjugated onto BMnNSs surface. ${ }^{103}$ Owing to the generation of $\mathrm{O}_{2}$ following the reaction of $\mathrm{MnO}_{2}$ nanosheets with $\mathrm{H}_{2} \mathrm{O}_{2}$, the BMnNSs-HPPH showed a significantly enhanced tumor growth inhibition when compared with HPPH. Similarly, in order to overcome hypoxia and improve the photodynamic effects of bladder cancer, Lin and colleagues prepared $\mathrm{HSA}-\mathrm{MnO}_{2}-\mathrm{Ce} 6 \mathrm{NPs} .{ }^{104}$ The $\mathrm{O}_{2}$ production of NPs in vivo and in vitro was investigated, while the oxygen content of the in situ bladder cancer increased 3.5-fold following injection of HSA$\mathrm{MnO}_{2}$-Ce6 nanoparticles when compared with preinjection.

To prevent the premature release of photosensitizer (PS) and increase oxygen concentration in solid tissues, $\mathrm{Ma}$ and colleagues developed an acidic $\mathrm{H}_{2} \mathrm{O}_{2}$-response core-shell $\mathrm{O}_{2}$-elevated PDT nanoplatform through the use of a $\mathrm{MnO}_{2}$ shell to encapsulate a $\mathrm{SiO}_{2}$-methylene blue core with a high PS payload. ${ }^{105}$ Following the intravenous injection of nanoparticles, the external $\mathrm{MnO}_{2}$ shell stops PS leaking into the blood until it reaches tumor tissue, avoiding phototoxicity to healthy cells. Acidic $\mathrm{H}_{2} \mathrm{O}_{2}$ in the tumor environment triggers the formation of $\mathrm{O}_{2}$ by $\mathrm{MnO}_{2}$ while it reduces $\mathrm{Mn}^{4+}$ to $\mathrm{Mn}^{2+}$, meaning it can selectively perform MRI while monitoring tumor therapy. For $\mathrm{pH} /$ $\mathrm{H}_{2} \mathrm{O}_{2}$-driven fluorescence/MR dual-mode guided cancer PDT, Liu constructed a black phosphorus $/ \mathrm{MnO}_{2}$ nanoplatform. ${ }^{106}$ In order to endow the specificity of nanoparticles for targeting tumors to enhance PDT, as reported by $\mathrm{He}$, the AS1411 aptamer was anchored to the surface of large pore silica nanoparticles in which $\mathrm{MnO}_{2}$ nanoparticles were grown in situ. ${ }^{107} \mathrm{Zhu}$ et al constructed a multifunctional therapeutic nanoplatform through the integration of the nanoscale metal-organic framework (NMOF), BSA, sulfadiazines (SDs), and $\mathrm{MnO}_{2}$ into a system. ${ }^{108}$ Porphyrins not only participate in the formation of NMOF as organic ligands but also act as photosensitizers. BSA is an ideal vehicle for endowing the multifunction nanoplatform with excellent biocompatibility and long circulation. SDs were used to provide active targeting of overexpressed carbonic anhydrase IX (CA IX) in tumor 
cells. In addition, the nanoplatform can alleviate tumor hypoxia by downregulating CA IX and catalyzing $\mathrm{H}_{2} \mathrm{O}_{2}$ to produce $\mathrm{O}_{2}$, which significantly enhances the PDT effect. This can be confirmed by the photocytotoxicity of $4 \mathrm{~T} 1$ cells and the reduced tumor volume. PDT is an effective strategy for eliminating primary tumors, but its effect on metastasis and recurrence is not obvious. In order to achieve oxygen-boosted immunogenic PDT in metastatic triple-negative breast cancer (mTNBC), Liang and colleagues designed a core-shell gold nanocage@manganese dioxide (AuNC@ $\mathrm{MnO}_{2}$ ) nanoparticle as a tumor microenvironment $\mathrm{pH} / \mathrm{H}_{2} \mathrm{O}_{2}$ responsive oxygen generator and a NIR-triggered ROS producer. ${ }^{109}$ The nanoplatform does not just achieve fluorescence/PA/MR multimodal imaging-guided $\mathrm{O}_{2}$-enhanced PDT for destroying primary tumors effectively, but can also induce immunogenic cell death with the release of a damage-related molecular pattern, subsequently inducing dendritic cell maturation and effector cell activation, thus arousing the systematic antitumor immune response against mTNBC, work which has made it possible to prevent tumor metastasis.

$\mathrm{Hao}^{110}$ and $\mathrm{Chu}^{101}$ state that once the NPs of the $\mathrm{MnO}_{2}$ shell-coated photosensitizer are taken up by the tumor cells, the endogenous $\mathrm{H}_{2} \mathrm{O}_{2}$ is catalyzed by the $\mathrm{MnO}_{2}$ shell to produce $\mathrm{O}_{2}$. At the same time, overexpressed GSH promotes the degradation of $\mathrm{MnO}_{2}$ to $\mathrm{Mn}^{2+}$ ions to enhance MRI. Fortunately, the reduction in GSH and generation of $\mathrm{O}_{2}$ demonstrate synergistic enhanced PDT to improve antitumor efficacy in vitro and in vivo. The TME-responsive $\mathrm{MnO}_{2}$ in this nanoplatform can generate oxygen to alleviate hypoxia. In addition, enhanced photosensitizer yield and elevated oxygen are conducive to the ultimate therapeutic effect. Based on the $\mathrm{MnO}_{2}$ shell-enhanced PDT, Hu et $\mathrm{al}^{111}$ and $\mathrm{Xu}$ et $\mathrm{al}^{112}$ loaded Dox on the designed nanoplatform to realize a tumor microenvironment-responsive multimodal imaging-monitoring chemo-photodynamic therapy. In contrast, $\mathrm{Bi}$ and colleagues used an $\mathrm{MnO}_{2}$ shell as the carrier of platinum(IV) (Pt(IV)) prodrugs, while intracellular GSH simultaneously reduced $\mathrm{MnO}_{2}$ and $\mathrm{Pt}(\mathrm{IV})$ prodrugs to achieve GSH-responsive MRI and drug release. ${ }^{113}$ Interestingly, as illustrated in Figure 5A, Zhang and colleagues developed nanocomposite, upconversion nanoparticles (UNCPs)@ $\mathrm{TiO}_{2} @ \mathrm{MnO}_{2}$, to overcome the deficiencies of PDT with insufficient oxygen, inefficient ROS generation, and low light penetration depth. ${ }^{114}$ Once the nanoplatform was taken up by tumor cells, intracellular $\mathrm{H}_{2} \mathrm{O}_{2}$ was
(A)
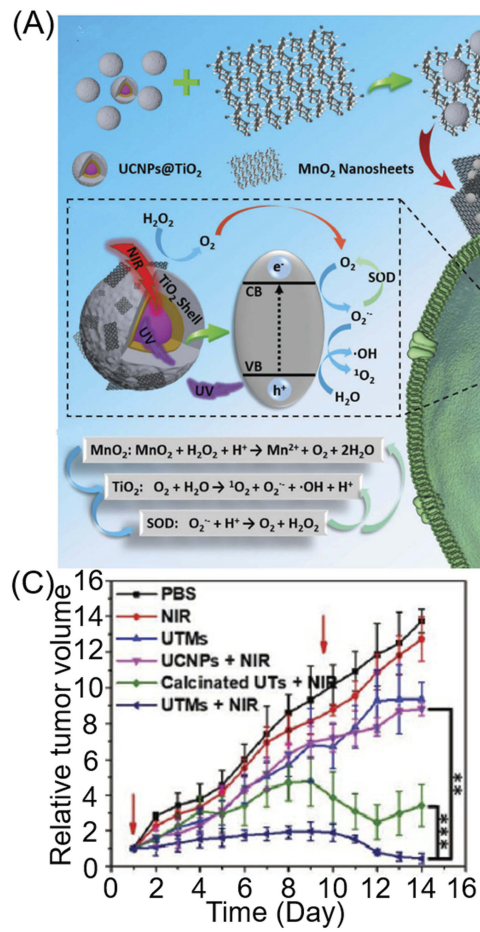
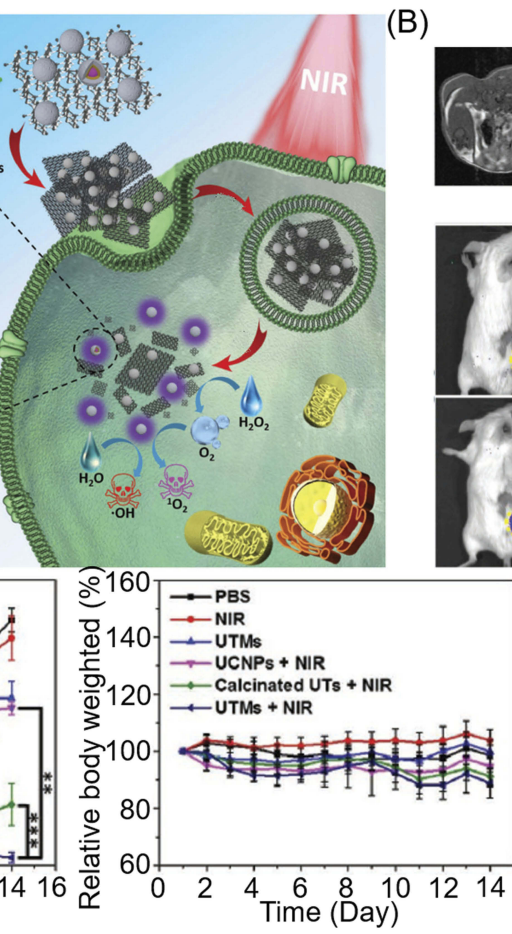

(B)
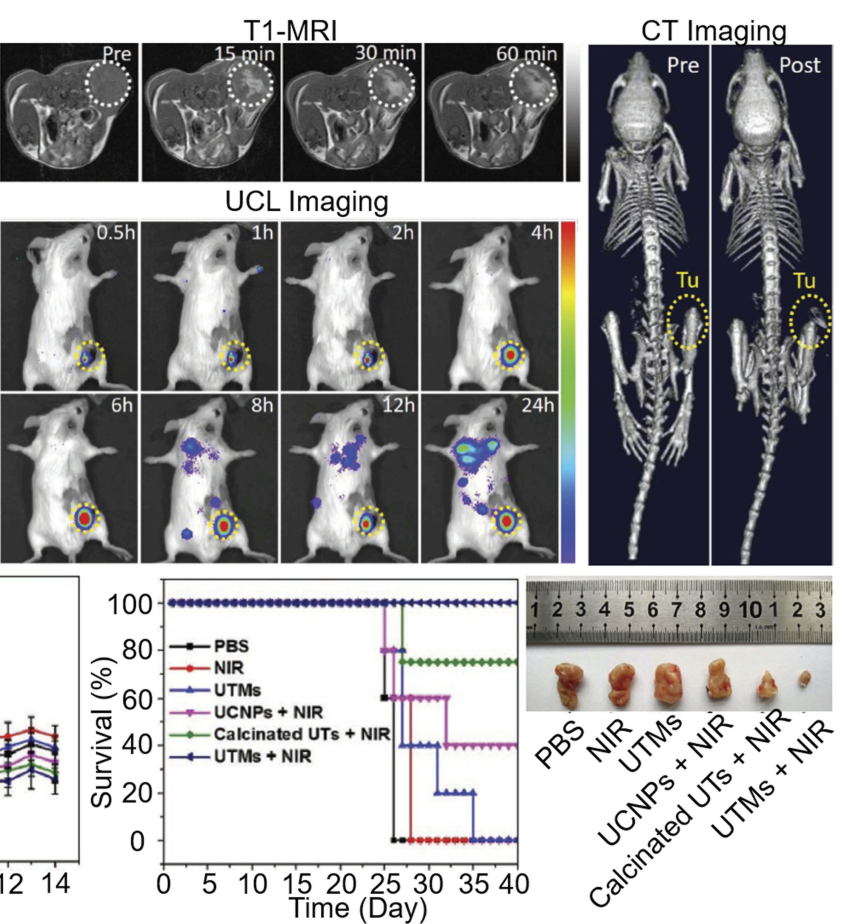

Figure 5 (A) Schematic illustration of (UNCPs)@TiO ${ }_{2} @ \mathrm{MnO}_{2} \mathrm{NPs}_{\text {for }} \mathrm{O}_{2}$ self-supplemented and ROS circulating amplified PDT. (B) TI-MR/UCL/CT imaging of tumors with (UNCPs)@TiO ${ }_{2} @ M_{n} \mathrm{O}_{2}$ NPs. (C) The treatment effect of PDT with (UNCPs)@TiO $\mathrm{CMnO}_{2}$ NPs. Reprinted with permission from Zhang C, Chen WH, Liu LH, Qiu WX, Yu WY, Zhang XZ. An $\mathrm{O}_{2}$ Self-Supplementing and Reactive-Oxygen-Species-Circulating Amplified Nanoplatform via $\mathrm{H}_{2} \mathrm{O} / \mathrm{H}_{2} \mathrm{O}_{2}$ Splitting for Tumor Imaging and Photodynamic Therapy. Advanced Functional Materials. 2017;27(43):I700626. ${ }^{114}$ Copyright $\odot 2017$ John Wiley and Sons.

Abbreviations: UCL, upconversion luminescence; UCNPs, upconversion nanoparticles; UTMs, UCNPs@TiO $@$ Mn $\mathrm{O}_{2}$; UTs, UCNPs@TiO2 core-shell-shell nanoparticles. 
catalyzed by $\mathrm{MnO}_{2}$ to generate $\mathrm{O}_{2}$ in situ. Given the degradation of $\mathrm{MnO}_{2}$ and $980 \mathrm{~nm}$ NIR laser irradiation, exposed UNCPs can effectively convert NIR into ultraviolet light to activate $\mathrm{TiO}_{2}$, after which they catalyze the splitting of $\mathrm{H}_{2} \mathrm{O}$ to produce toxic $\operatorname{ROS}\left({ }^{1} \mathrm{O}_{2}\right.$ and $\left.\cdot \mathrm{OH}\right)$ for deep tumor treatment. In addition, the by-product of water-splitting, superoxide anion radicals $\left(\mathrm{O}_{2}{ }^{-}\right)$, can be catalyzed using intracellular superoxide dismutase (SOD) to generate more $\mathrm{H}_{2} \mathrm{O}_{2}$ and $\mathrm{O}_{2}$. This cyclic reaction allows both $\mathrm{O}_{2}$ and ROS to be regenerated by decomposition of $\mathrm{MnO}_{2}$, while upconversion luminescence and MR imaging are activated in turn, which can significantly improve PDT efficiency and tumor imaging ability (see Figure $5 \mathrm{~B}$ and $\mathrm{C}$ ). This has great potential in antitumor.

\section{$\mathrm{MnO}_{2} \mathrm{NPs}$ For Enhanced Photothermal Therapy And MRI}

Photothermal therapy (PTT) is a new cancer treatment research technology which uses nanomaterials to convert near-infrared light energy into thermal energy ablation tumor. ${ }^{115}$ The therapy has attracted great attention in recent years due to its remarkable advantages, such as being noninvasive, leading to a rapid recovery time and high spacetime control. ${ }^{116}$ Imaging probes are a key component of theragnostics which can report the presence of tumors as well as monitoring and evaluating therapeutic effects. ${ }^{117}$
$\mathrm{MnO}_{2}$, a magnetic resonance $\mathrm{CA}$ which responds to tumor microenvironment, is widely used in MRI-guided PTT.

Pan and colleagues synthesized a nanotheranostic agent for the cross-linking of indocyanine green on BSA-stabilized $\mathrm{MnO}_{2}$ surface (BMI). ${ }^{90}$ This BMI has an ultrahigh T1 relaxation rate of $70.6 \mathrm{mM}^{-1} \mathrm{~s}^{-1}$ at $0.5 \mathrm{~T}$. Tumors of $4 \mathrm{~T} 1$ cellsbearing Balb/c mice completely disappeared after 13 days of intratumoral administration and irradiation with $808 \mathrm{~nm}$ laser at a power of $0.5 \mathrm{~W} \mathrm{~cm}^{-2}$. For the first time, as shown in Figure 6A, Liu and colleagues proposed that ultrathin 2D $\mathrm{MnO}_{2}$ nanosheets have T1-weighted magnetic resonance imaging capabilities of $\mathrm{pH}$ and redox response (see Figure 6B), and the ultrathin $2 \mathrm{D} \mathrm{MnO}_{2}$ nanosheets also have inherently high photothermal conversion capability ( $\eta: 21.4 \%$ ), in vitro and in vivo photothermal experiments systematically demonstrated that $2 \mathrm{D} \mathrm{MnO}_{2}$ nanosheets have a high PTT efficiency in response to external near-infrared radiation for inhibiting tumor growth (see Figure 6C). ${ }^{118}$ In view of the excellent physicochemical properties of $\mathrm{MnO}_{2}$ as well as the large size of $2 \mathrm{D} \mathrm{MnO}_{2}$ nanosheets, $\mathrm{Fu}$ et al reported a simple method for the growth of $\mathrm{MnO}_{2}$ shells on various cores which are mediated by cationic polyelectrolytes. ${ }^{119}$ The $\mathrm{Cu}_{2-\mathrm{x}} \mathrm{Se} @ \mathrm{MnO}_{2}$ nanoparticles which have been synthesized by this method show triple-enhanced magnetic resonance contrast in the tumor environment, while the $\mathrm{Cu}_{2-\mathrm{x}} \mathrm{Se}$

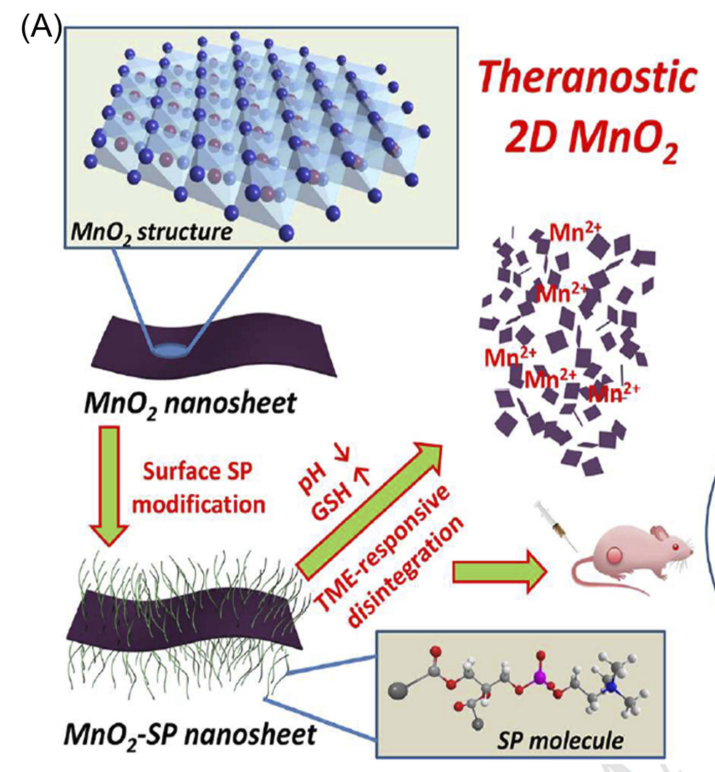

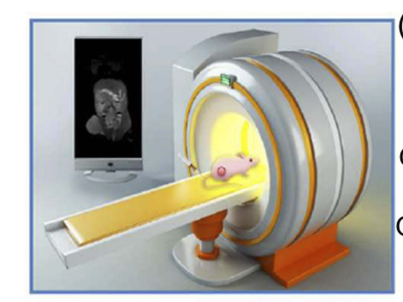

I: TME-responsive MRI

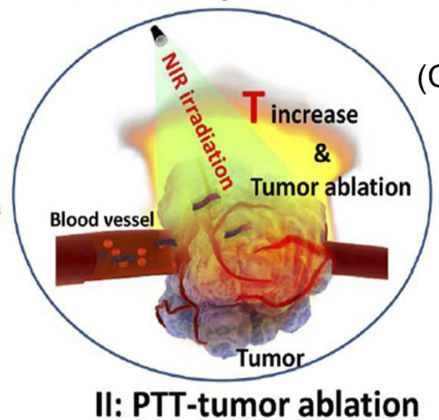

II: PTT-tumor ablation
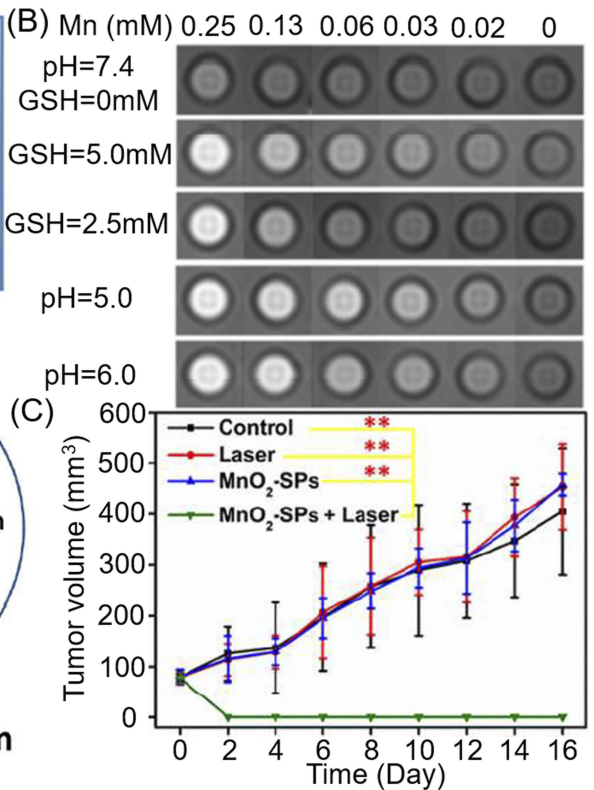

Figure 6 (A) Schematic illustration of synthetic procedure for $\mathrm{MnO}_{2}$-SPs nanosheets and their specific functions for tumor theranostics with TME sensitivity. (B) TI-weighted MR imaging of $\mathrm{MnO}_{2}-\mathrm{SPs}$ in buffer solution at differing $\mathrm{PHs}$ (6.0 and 5.0) and differing GSH concentrations (2.5 and $5.0 \mathrm{mM}$ ) following incubation for 2 hours at $37^{\circ} \mathrm{C}$. (C) Time-

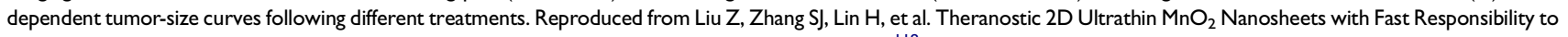
Endogenous Tumor Microenvironment and Exogenous NIR Irradiation. Biomaterials. 2018;155:54-63. ${ }^{118}$ Copyright @ 20I7, with permission from Elsevier.

Abbreviation: SP, soybean phospholipid. 
core has strong absorption in second near-infrared (NIR II) window, demonstrating excellent PTT effect in vivo and in vitro. Peng and colleagues developed Prussian blue $/ \mathrm{MnO}_{2}$ hybrid nanoparticle of less than $50 \mathrm{~nm}$ using a one-pot method for PA/T1/T2 MR three-mode imaging-guided oxygen-regulated PTT in breast cancer. ${ }^{24}$ In view of the heterogeneous heat distribution in tumor tissues ${ }^{120}$ and the rapid heat shock protein (HSP) production ${ }^{121}$ which leads to PTT treatment resistance and reduced therapeutic efficacy, it is urgent that we design versatile nanoparticles which can integrate PTT with other therapies for synergistic treatment. Based on this, Jin et al constructed a novel theragnostic agent, Co $-\mathrm{P} @ \mathrm{mSiO}_{2} @ \mathrm{Dox}-\mathrm{MnO}_{2}$, for pH-activated T1/T2 dualmodal magnetic MRI-guided chemo-photothermal synergistic therapy both in vitro and in vivo. ${ }^{122}$ In a weak acidic tumor environment, the $\mathrm{MnO}_{2}$-gated dissolution not only enhanced T1-weighted MRI but also achieved on-demand drug release. This stimuli-responsive nanoagent provided more accurate diagnostic information, hugely improved the therapeutic effect and effectively reduced side effects.

In terms of chemo-photothermal synergistic therapy, $\mathrm{Li}$ and colleagues designed poly(ethylene glycol)thiol (PEG$\mathrm{SH})$ modified $\mathrm{CuS}-\mathrm{Au}-\mathrm{MnO}_{2}$ ternary Janus nanoparticles (JNPs). ${ }^{123}$ In these ternary JNPs, the pH-responsive mesoporous $\mathrm{MnO}_{2}$ acted not only as a $\mathrm{T} 1$ magnetic resonance CA but also as a carrier for the hydrophobic drug celastrol (CST). In addition, Au endowed ternary JNPs with CT imaging capability, and the localized surface plasmon resonance (LSPR) coupling effect of CuS surface and Au core enabled it to perform hyperthermia at $1064 \mathrm{~nm}$ in the NIRII window to ablate deep tissue tumors. Similarly, Zhang and colleagues reported a GSH-activated nanoagent, $\mathrm{SiO}_{2} @ \mathrm{Au} @ \mathrm{MnO}_{2}-\mathrm{Dox} / \mathrm{AS} 1411$, for magnetic resonance/ fluorescence imaging-guided synergistic chemo-photothermal therapy for hypoxic solid tumors in vitro and in vivo. ${ }^{124}$ An example of this combination of photothermal therapy and radiotherapy comes from Yang et al, who designed $\mathrm{WS}_{2}$-based nanocomposites with iron oxide nanoparticles (IONPs) and $\mathrm{MnO}_{2}$ shell via self-assembly. ${ }^{125} \mathrm{Here}, \mathrm{MnO}_{2}$ was used as a $\mathrm{pH}$-activated T1 CA and IONPs as a pH-inert T2 CA to achieve tumor $\mathrm{pH}-$-responsive MRI. The strong NIR absorption of $\mathrm{WS}_{2}$ enabled photoacoustic imaging capacity, while the near-infrared and X-ray absorption of $\mathrm{WS}_{2}$ were performed for PTT and enhanced radiotherapy, respectively. More crucially, $\mathrm{MnO}_{2}$ catalyzed overexpression of $\mathrm{H}_{2} \mathrm{O}_{2}$ produced $\mathrm{O}_{2}$ to alleviate tumor hypoxia and so enhance therapeutic effects. Cao and colleagues prepared $\mathrm{MnO}_{2} / \mathrm{Cu}_{2-\mathrm{x}} \mathrm{S}$-siRNA nanoparticles by loading $\mathrm{Cu}_{2-\mathrm{x}} \mathrm{S}$ onto the surface of $\mathrm{MnO}_{2}$ nanosheets and then modifying them with HSP 70 siRNA. ${ }^{126}$ Once NPs were taken up by tumor cells, $\mathrm{MnO}_{2}$ nanosheets were reduced to $\mathrm{Mn}^{2+}$ ions which enhance the MRI contrast and initiated the decomposition of $\mathrm{H}_{2} \mathrm{O}_{2}$ to $\mathrm{O}_{2}$ to alleviate tumor hypoxia. The NIR absorption of $\mathrm{Cu}_{2-\mathrm{x}} \mathrm{S}$ can be used for PA and photothermal (PT) imaging. Under a single NIR laser irradiation, NPs exhibited a three-mode imaging-guided enhanced PTT/PDT due to siRNA-mediated blockade heat shock response as well as $\mathrm{MnO}_{2}$-related amelioration of tumor hypoxia.

\section{$\mathrm{MnO}_{\mathrm{x}}$-Based Nanoparticles In Tumor Diagnosis And Therapy}

The oxidation state of manganese oxide can be distinguished using classical material science characterization techniques such as X-ray diffraction (XRD), X-ray photoelectron spectroscopy (XPS), and so on. However, when the size of the material reaches the nanoscale, the broadening and weakening of the peak means that this characterization becomes extremely challenging. Therefore, some researchers described the nanostructures simply as $\mathrm{MnO}_{\mathrm{x}}$ to avoid inaccuracies. ${ }^{26}$ Rosenholm and colleagues modified amorphous $\mathrm{MnO}_{\mathrm{x}}$ with PVP and poly(acrylic acid) (PAA) to bring a negative charge to the surface $(-25.7 \pm 1.47 \mathrm{mV})$, while the hydrodynamic properties and biocompatibility were found to be significantly better than crystallization $(\mathrm{MnO})$. Additionally, the relaxation time of the nanoprobe was approximately 10 times lower than that of the crystalline particles. ${ }^{127}$ Ren and colleagues used $\mathrm{MnO}_{\mathrm{x}}$ coated superparamagnetic iron oxide nanoparticles as gates to control the CPT release from mesoporous silica and so achieve the TME-responsive T1/T2 dual-mode MRI-guided pancreatic cancer chemotherapy both in vitro and in vivo. ${ }^{128}$ Similarly, Gao and colleagues labeled technetium- $99\left({ }^{99 \mathrm{~m}} \mathrm{Tc}\right)$ on the surface of the $\mathrm{MnO}_{\mathrm{x}}$-based mesoporous silica nanoparticles $\left(\mathrm{MnO}_{\mathrm{x}}-\mathrm{MSN}\right)$ to integrate SPECT and MRI imaging modalities for both excellent sensitivity and high spatial resolution. ${ }^{129}$ The radiolabeling yield was as high as 99.1 $\pm 0.6 \%$, while the $r_{1}$ value of the nanostructures could reach $6.60 \mathrm{mM}^{-1} \mathrm{~s}^{-1}$ as a result of the $\mathrm{pH}$-responsive nature of $\mathrm{MnO}_{\mathrm{x}}-\mathrm{MSN}$. Additionally, the drug loading rate of $\mathrm{MnO}_{\mathrm{x}}-$ MSN to Dox was as high as $382 \mathrm{mg} / \mathrm{g}$, while the degradation of $\mathrm{MnO}_{\mathrm{x}}$ in a weak acid environment triggers on-demand drug release. Zhang and colleagues ingeniously integrated $\mathrm{MnO}_{\mathrm{x}} \mathrm{NPs}$ into hollow mesoporous carbon nanocapsules via an in situ framework redox method. In the weak acidic environment, the longitudinal relaxation of $\mathrm{pH}$-sensitive 
$\mathrm{MnO}_{\mathrm{x}} \mathrm{NPs}$ increased 52.5 times to $10.5 \mathrm{mM}^{-1} \mathrm{~s}^{-1}{ }^{130}$ The carbonaceous framework could not only react with $\mathrm{MnO}_{4}$ to form $\mathrm{MnO}_{\mathrm{x}} \mathrm{NPs}$ in situ but could also connect to the aromatic drug molecules through $\pi-\pi$ stacking. Drug release behavior which was triggered by different $\mathrm{pH}$ and high intensity focused ultrasound (HIFU) systematically confirmed the findings of $\mathrm{pH}$-/HIFU-triggered Dox on-demand release as well as enhanced cancer cell chemotherapy. In contrast, Dai and colleagues grew $\mathrm{MnO}_{\mathrm{x}}$ nanoparticles in situ on the surface of tantalum carbide $\left(\mathrm{Ta}_{4} \mathrm{C}_{3}\right)$ MXene nanosheets and created further surface organic modification by soybean phospholipids (SP) for three-mode imaging-guiding PTT. ${ }^{131}$ Similarly, the integrated nanoparticles, $\mathrm{MnO}_{\mathrm{x}} /$ $\mathrm{Ta}_{4} \mathrm{C}_{3}$-SP, had TME-responsive T1-weighted MR imaging capabilities (see Figure 7A and B), while the photothermal conversion performance of $\mathrm{Ta}_{4} \mathrm{C}_{3}$ endowed $\mathrm{MnO}_{\mathrm{x}} / \mathrm{Ta}_{4} \mathrm{C}_{3}$ NPs with photoacoustic imaging and photoconductive tumor ablation capabilities, in which tantalum was also used as a high-performance CT imaging contrast agent (see Figure 7C-E). This work provided a new strategy for both cancer diagnosis and photothermal therapy.

\section{Conclusion And Outlook}

MRI is the fastest growing molecular imaging technology due to its non-invasive nature, high spatial resolution, non-ionizing radiation, soft tissue imaging, and so on. In order to improve the sensitivity of MRI, the study of CAs has attracted wide attention. Furthermore, due to their good biocompatibility, relatively high magnetization spin and rapid water proton exchange rate, MONs, rather than Gd-based, have been developed as a T1 CA, and have a huge clinical significance for the detection and diagnosis of cancer. This review summarizes recent advances in MONs-related multimodal imaging CAs and nanotheranostic agents, including $\mathrm{MnO}, \mathrm{Mn}_{3} \mathrm{O}_{4}, \mathrm{MnO}_{2}$, and $\mathrm{MnO}_{\mathrm{x}}$ as $\mathrm{MR}$ CAs in MRI, bimodal or multimodal imaging, and imaging-guided therapy.

While the broad prospects of the MONs nanoplatform have been noted, they are still in the early lab stage. Similar to all nanostructures, the small size of nanomaterials gives them excellent physical and chemical properties, but their nanotoxicity is still unclear. For MONs, whether or not the crystal structure weakens the neurotoxicity of manganese itself requires further study. More importantly, the more
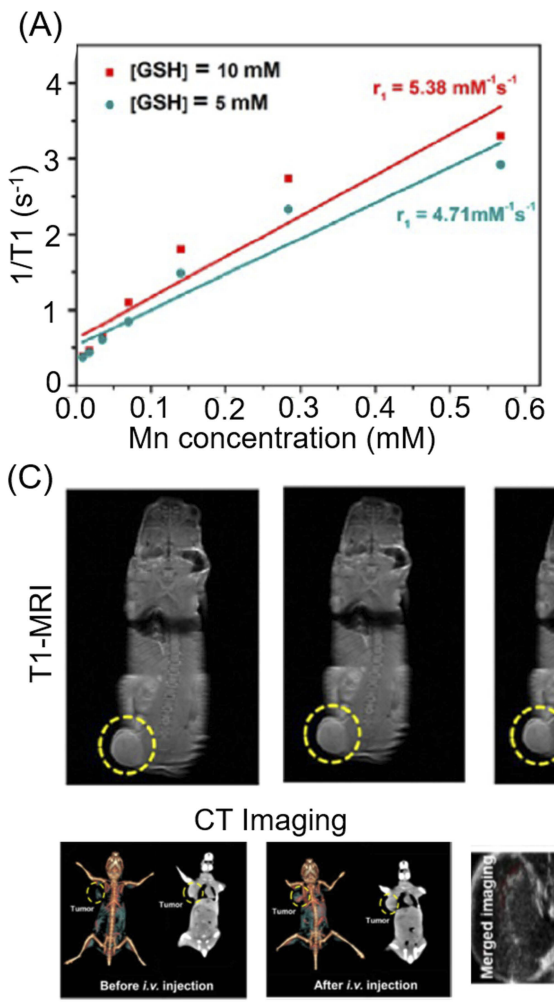

(B)
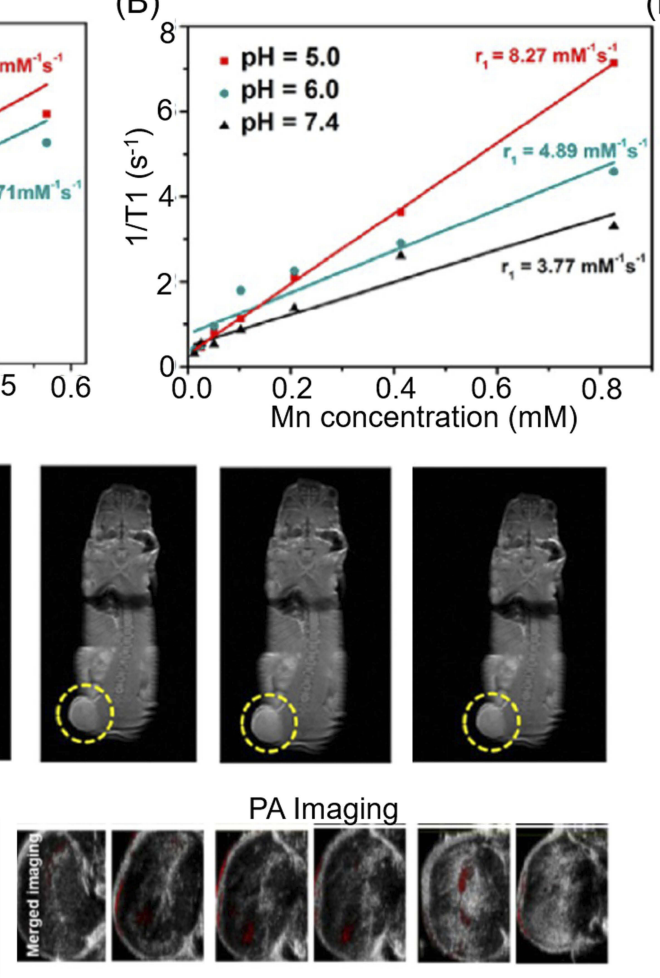

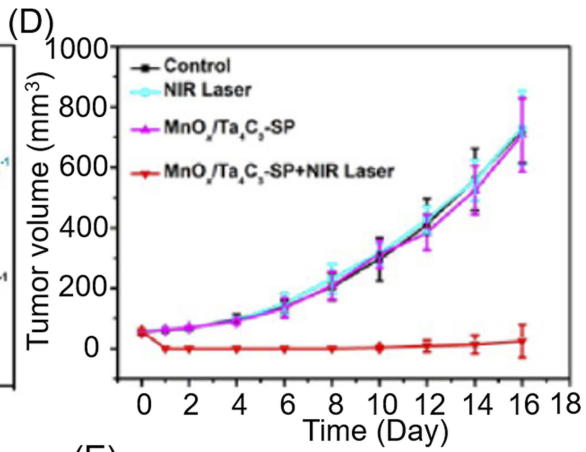

(E)

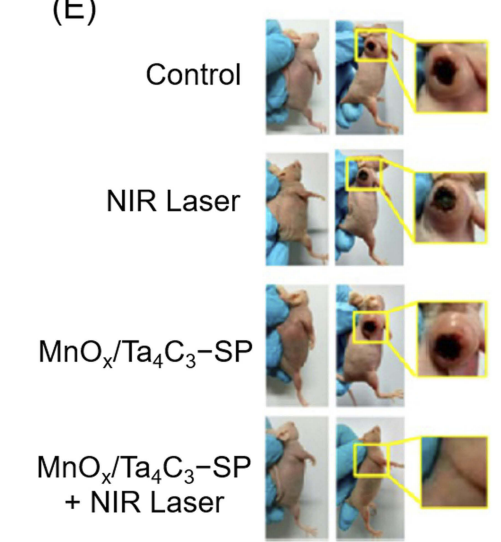

Figure $7 \mathrm{I} / \mathrm{TI}$ vs $\mathrm{Mn}$ concentration for $\mathrm{MnO}_{x} / \mathrm{Ta}_{4} \mathrm{C}_{3}-\mathrm{SP}$ composite nanosheets in buffer solution (A) at different GSH concentrations and (B) at different $\mathrm{pH}$ values after soaking for 3 hours. (C) Corresponding TI-weighted imaging of $4 \mathrm{TI}$ tumor-bearing mice after intravenous administration of $\mathrm{MnO}_{x} / \mathrm{Ta}_{4} \mathrm{C}_{3}-\mathrm{SP}$ composite nanosheets for prolonged time intervals. (D) Time-dependent tumor-growth curves of four groups (control, NIR laser, $\mathrm{MnO}_{x} / \mathrm{Ta}_{4} \mathrm{C}_{3}-\mathrm{SP}$, and $\mathrm{MnO}_{\times} / \mathrm{Ta}_{4} \mathrm{C}_{3}-\mathrm{SP}+\mathrm{NIR}$ laser groups) after receiving different disposes. (E) Digital images of tumors from each group at the end of the various treatments. Reproduced from Dai $C$, Chen $Y$, Jing $X X$, et al. TwoDimensional Tantalum Carbide (MXenes) Composite Nanosheets for Multiple Imaging-Guided Photothermal Tumor Ablation. ACS Nano. 20I7;। (I2):I2696-I27I2. ${ }^{131}$ Copyright (c) 2017 American Chemical Society. 
functionality of a single nanoprobe is achieved at the expense of increasing complexity. The complex structures required to achieve versatility present enormous technical challenges in the construction and assembly of these nanoprobes, such as colloidal stability, controllability of experimental processes, reproducibility, and cost control. These challenges increase the difficulty of purifying the resulting nanoprobe, as well as the monodispersity of the final product, and lead to storage and shelf-life issues. These are all major challenges for the clinical transformation of MONs NPs.

Based on the evidence cited here, further research is needed to obtain a robust, reproducible experimental protocol, and then to fully characterize and verify the properties and functions of each component of the nanoprobes in various models in vitro and in vivo. In addition, monitoring the long-term toxicity, immunotoxicity, and neurotoxicity of NPs are also essential. Efficient delivery of NPs at specific locations in the body is currently a major obstacle to tumor imaging and therapy, while the screening of tumor markers is the key to addressing probe targeting specificity issues. As science and technology develop, if these problems can be effectively solved, the engineering MONs could be used as a safe nanoplatform for tumor diagnosis, monitoring, and treatment in clinic.

\section{Acknowledgments}

This work was supported, in part, by the National Key R\&D Program of China under Grant No. 2018YFC0910602, the National Natural Science Foundation of China under Grant Nos. 11727813, 81627807, 91859109, 81571725, 81871397, 81701853, 81660505 and 81530058, the Fok Ying-Tong Education Foundation of China under Grant 161104, the Program for the Young Top-notch Talent of Shaanxi Province, the Research Fund for Young Star of Science and Technology in Shaanxi Province under Grant No. 2018KJXX-018, the Natural Science Basic Research Plan in Shaanxi Province of China under Grant No. 2018JM7072, and the Fundamental Research Funds for the Central Universities (JB181203).

\section{Disclosure}

The authors report no conflicts of interest in this work.

\section{References}

1. Herschman HR. Molecular imaging: looking at problems, seeing solutions. Science. 2003;302(5645):605-608. doi:10.1126/science.1090585
2. Zhang K, Chen HR, Li P, et al. Marriage strategy of structure and composition designs for intensifying ultrasound \& MR \& CT trimodal contrast imaging. ACS Appl Mater Inter. 2015;7 (33):18590-18599. doi:10.1021/acsami.5b04999

3. Weissleder R, Pittet MJ. Imaging in the era of molecular oncology. Nature. 2008;452(7187):580-589. doi:10.1038/nature06917

4. Wang LHV, Hu S. Photoacoustic tomography: in vivo imaging from organelles to organs. Science. 2012;335(6075):1458-1462. doi:10.1126/science.1216210

5. Zhan YH, Shi SX, Ehlerding EB, et al. Radiolabeled, antibodyconjugated manganese oxide nanoparticles for tumor vasculature targeted positron emission tomography and magnetic resonance imaging. ACS Appl Mater Inter. 2017;9(44):38304-38312. doi:10.1021/acsami.7b12216

6. Sun C, Lee JSH, Zhang MQ. Magnetic nanoparticles in MR imaging and drug delivery. Adv Drug Deliver Rev. 2008;60(11):12521265. doi:10.1016/j.addr.2008.03.018

7. Na HB, Song IC, Hyeon T. Inorganic nanoparticles for MRI contrast agents. Adv Mater. 2009;21(21):2133-2148. doi:10.1002/ adma.v21:21

8. Lei M, Fu C, Cheng X, et al. Activated surface charge-reversal manganese oxide nanocubes with high surface-to-volume ratio for accurate magnetic resonance tumor imaging. Adv Funct Mater. 2017;27(30):1700978. doi:10.1002/adfm.201700978

9. Balci NC, Semelka RC. Contrast agents for MR imaging of the liver. Radiol Clin N Am. 2005;43(5):887-898. doi:10.1016/j. rcl.2005.05.004

10. Zhao Z, Zhou Z, Bao J, et al. Octapod iron oxide nanoparticles as high-performance $\mathrm{T} 2$ contrast agents for magnetic resonance imaging. Nat Commun. 2013;4:2266. doi:10.1038/ncomms3266

11. Caravan P. Strategies for increasing the sensitivity of gadolinium based MRI contrast agents. Chem Soc Rev. 2006;35(6):512-523. doi:10.1039/b510982p

12. Idee JM, Port M, Dencausse A, Lancelot E, Corot C. Involvement of gadolinium chelates in the mechanism of nephrogenic systemic fibrosis: an update. Radiol Clin $N$ Am. 2009;47(5):855-869. doi:10.1016/j.rcl.2009.06.006

13. Thomsen HS, Morcos SK, Almen T, et al. Nephrogenic systemic fibrosis and gadolinium-based contrast media: updated ESUR Contrast Medium Safety Committee guidelines. Eur Radiol. 2013;23(2):307-318. doi:10.1007/s00330-012-2597-9

14. Xiang Y, Li NL, Guo LJ, et al. Biocompatible and $\mathrm{pH}$-sensitive MnO-loaded carbonaceous nanospheres (MnO@CNSs): a theranostic agent for magnetic resonance imaging-guided photothermal therapy. Carbon. 2018;136:113-124. doi:10.1016/j.carbon. 2018.04.058

15. Bulte JWM. In vivo MRI cell tracking: clinical studies. Am J Roentgenol. 2009;193(2):314-325. doi:10.2214/AJR.09.3107

16. Kostura L, Kraitchman DL, Mackay AM, Pittenger MF, Bulte JWM. Feridex labeling of mesenchymal stem cells inhibits chondrogenesis but not adipogenesis or osteogenesis. NMR Biomed. 2004;17(7):513-517. doi:10.1002/nbm.925

17. Neves HR, Bini RA, Barbosa JHO, Salmon CEG, Varanda LC. Dextran-coated antiferromagnetic $\mathrm{MnO}$ nanoparticles for a T-1MRI contrast agent with high colloidal stability. Part Part Syst Char. 2016;33(3):167-176. doi:10.1002/ppsc.201500251

18. Hu H, Liu SL, Li D, et al. The synthesis of lanthanide-doped GdVO4 ultrathin nanosheets with great optical and paramagnetic properties for FRET biodetection and in vivo MR imaging. J Mater Chem B. 2014;2(25):3998-4007. doi:10.1039/C4TB00144C

19. Fitsanakis VA, Zhang N, Avison MJ, Gore JC, Aschner JL, Aschner $\mathrm{M}$. The use of magnetic resonance imaging (MRI) in the study of manganese neurotoxicity. Neurotoxicology. 2006;27(5):798-806. doi:10.1016/j.neuro.2006.03.001

20. Takeda A. Manganese action in brain function. Brain Res Rev. 2003;41(1):79-87. 
21. Guilarte TR. Manganese neurotoxicity: new perspectives from behavioral, neuroimaging, and neuropathological studies in humans and non-human primates. Front Aging Neurosci. 2013;5:23. doi:10.3389/fnagi.2013.00023

22. Pan D, Caruthers SD, Hu G, et al. Ligand-directed nanobialys as theranostic agent for drug delivery and manganese-based magnetic resonance Imaging of vascular targets. J Am Chem Soc. 2008;130 (29):9186-9187. doi:10.1021/ja801482d

23. Pan DPJ, Schmieder AH, Wickline SA, Lanza GM. Manganesebased MRI contrast agents: past, present, and future. Tetrahedron. 2011;67(44):8431-8444. doi:10.1016/j.tet.2011.07.076

24. Peng JR, Dong ML, Ran B, et al. "One-for-AII"-type, biodegradable prussian blue/manganese dioxide hybrid nanocrystal for trimodal imaging-guided photothermal therapy and oxygen regulation of breast cancer. ACS Appl Mater Inter. 2017;9(16):13875-13886. doi:10.1021/acsami.7b01365

25. Hsu BYW, Kirby G, Tan A, Seifalian AM, Li X, Wang J. Relaxivity and toxicological properties of manganese oxide nanoparticles for MRI applications. RSC Adv. 2016;6(51):45462-45474. doi:10.1039/C6RA04421B

26. Garcia-Hevia L, Banobre-Lopez M, Gallo J. Recent progress on manganese-based nanostructures as responsive MRI contrast agents. Chem-Eur J. 2019;25(2):431-441. doi:10.1002/chem.201802851

27. Li J, Wu C, Hou P, Zhang M, Xu K. One-pot preparation of hydrophilic manganese oxide nanoparticles as T1 nano-contrast agent for molecular magnetic resonance imaging of renal carcinoma in vitro and in vivo. Biosens Bioelectron. 2018;102:1-8. doi:10.1016/j.bios.2017.10.047

28. Huang HT, Yue T, Xu K, Golzarian J, Yu JH, Huang J. Fabrication and evaluation of tumor-targeted positive MRI contrast agent based on ultrasmall MnO nanoparticles. Colloid Surf B. 2015;131:148-154.

29. Hsu BYW, Wang M, Zhang Y, et al. Silica-F127 nanohybridencapsulated manganese oxide nanoparticles for optimized T-1 magnetic resonance relaxivity. Nanoscale. 2014;6(1):293-299. doi:10.1039/c3nr04378a

30. Costanzo M, Scolaro L, Berlier G, et al. Cell uptake and intracellular fate of phospholipidic manganese-based nanoparticles. Int J Pharmaceut. 2016;508(1-2):83-91. doi:10.1016/j.ijpharm. 2016.05.019

31. Chevallier P, Walter A, Garofalo A, et al. Tailored biological retention and efficient clearance of pegylated ultra-small $\mathrm{MnO}$ nanoparticles as positive MRI contrast agents for molecular imaging. J Mater Chem B. 2014;2(13):1779-1790. doi:10.1039/C3TB21634A

32. Huang HT, Yue T, Xu YY, et al. PEGylation of MnO nanoparticles via catechol-Mn chelation to improving T-1-weighted magnetic resonance imaging application. J Appl Polym Sci. 2015;132 (31):42360. doi:10.1002/app.42360

33. Gallo J, Alam IS, Lavdas I, Wylezinska-Arridge M, Aboagye EO, Long NJ. RGD-targeted $\mathrm{MnO}$ nanoparticles as T1contrast agents for cancer imaging - the effect of PEG length in vivo. J Mater Chem B. 2014;2(7):868-876. doi:10.1039/C3TB21422B

34. Chen N, Shao C, Qu Y, et al. Folic acid-conjugated MnO nanoparticles as a $\mathrm{T} 1$ contrast agent for magnetic resonance imaging of tiny brain gliomas. ACS Appl Mater Interfaces. 2014;6(22):1985019857. doi:10.1021/am505223t

35. Hu X, Ji Y, Wang M, et al. Water-soluble and biocompatible $\mathrm{MnO} @$ PVP nanoparticles for MR imaging in vitro and in vivo. $J$ Biomed Nanotechnol. 2013;9(6):976-984. doi:10.1166/jbn.2013. 1602

36. Douglas FJ, MacLaren DA, Tuna F, Holmes WM, Berry CC, Murrie M. Formation of octapod MnO nanoparticles with enhanced magnetic properties through kinetically-controlled thermal decomposition of polynuclear manganese complexes. Nanoscale. 2014;6 (1):172-176. doi:10.1039/c3nr04832b
37. Peng YK, Lui CNP, Chen YW, et al. Engineering of single magnetic particle carrier for living brain cell imaging: a tunable T-1-/T2-/dual-modal contrast agent for magnetic resonance imaging application. Chem Mater. 2017;29(10):4411-4417. doi:10.1021/acs. chemmater.7b00884

38. Peng E, Wang FH, Tan SH, Zheng BW, Li SFY, Xue JM. Tailoring a two-dimensional graphene oxide surface: dual T-1 and T-2 MRI contrast agent materials. J Mater Chem B. 2015;3(28):5678-5682. doi:10.1039/C5TB00902B

39. Zheng YY, Zhang H, Hu YP, Bai L, Xue JY. MnO nanoparticles with potential application in magnetic resonance imaging and drug delivery for myocardial infarction. Int J Nanomed. 2018;13:61776188. doi:10.2147/IJN.S176404

40. Chen N, Shao C, Li S, et al. Cy5.5 conjugated MnO nanoparticles for magnetic resonance/near-infrared fluorescence dual-modal imaging of brain gliomas. J Colloid Interf Sci. 2015;457:27-34. doi:10.1016/j.jcis.2015.06.046

41. Hsu BYW, Ng M, Tan A, et al. pH-activatable MnO-based fluorescence and magnetic resonance bimodal nanoprobe for cancer imaging. Adv Healthc Mater. 2016;5(6):721-729. doi:10.1002/ adhm.201500908

42. Lai JX, Wang TJ, Wang H, Shi FQ, Gu W, Ye L. MnO nanoparticles with unique excitation-dependent fluorescence for multicolor cellular imaging and MR imaging of brain glioma. Microchim Acta. 2018;185(4):244. doi:10.1007/s00604-018-2779-5

43. Banerjee A, Bertolesi GE, Ling CC, et al. Bifunctional pyrrolidin-2-one terminated manganese oxide nanoparticles for combined magnetic resonance and fluorescence imaging. ACS Appl Mater Interfaces. 2019;11 (14):13069-13078. doi:10.1021/acsami.8b21762

44. Li S, Shao $\mathrm{C}, \mathrm{Gu} \mathrm{W}$, et al. Targeted imaging of brain gliomas using multifunctional Fe3O4/MnO nanoparticles. RSC Adv. 2015;5 (42):33639-33645. doi:10.1039/C5RA01069A

45. Liu Y, Lv XL, Liu H, et al. Porous gold nanocluster-decorated manganese monoxide nanocomposites for microenvironment-activatable MR/photoacoustic/CT tumor imaging. Nanoscale. 2018;10 (8):3631-3638. doi:10.1039/c7nr08535d

46. Liu JN, Bu WB, Shi JL. Chemical design and synthesis of functionalized probes for imaging and treating tumor hypoxia. Chem Rev. 2017;117(9):6160-6224. doi:10.1021/acs.chemrev.6b00525

47. Ni DL, Jiang DW, Valdovinos HF, et al. Bioresponsive polyoxometalate cluster for redox-activated photoacoustic imaging-guided photothermal cancer therapy. Nano Lett. 2017;17(5):3282-3289. doi:10.1021/acs.nanolett.7b00995

48. Lu Y, Zhang L, Li J, et al. MnO nanocrystals: a platform for integration of MRI and genuine autophagy induction for chemotherapy. Adv Funct Mater. 2013;23(12):1534-1546. doi: $10.1002 /$ adfm. 201202233

49. Wei J, Yu C, Wang L, et al. Cytotoxicity of mitochondrial-targeting silica-coated manganese oxide nanoparticles. Sci China Chem. 2015;58(10):1537-1543. doi:10.1007/s11426-015-5374-1

50. Howell M, Mallela J, Wang C, et al. Manganese-loaded lipid-micellar theranostics for simultaneous drug and gene delivery to lungs. J Control Release. 2013;167(2):210-218. doi:10.1016/j.jconrel.2013.01.029

51. Wang D, Lin $\mathrm{H}$, Zhang $\mathrm{G}$, et al. Effective $\mathrm{pH}$-activated theranostic platform for synchronous magnetic resonance imaging diagnosis and chemotherapy. ACS Appl Mater Inter. 2018;10(37):3111431123. doi:10.1021/acsami.8b11408

52. Abbasi AZ, Prasad P, Cai P, et al. Manganese oxide and docetaxel co-loaded fluorescent polymer nanoparticles for dual modal imaging and chemotherapy of breast cancer. $J$ Control Release. 2015;209:186-196. doi:10.1016/j.jconrel.2015.04.020

53. Wang S, Zhang Q, Yang P, et al. Manganese oxide-coated carbon nanotubes as dual-modality lymph mapping agents for photothermal therapy of tumor metastasis. ACS Appl Mater Interfaces. 2016;8(6):3736-3743. doi:10.1021/acsami.5b08087 
54. Zhou LH, Wu YY, Meng XQ, et al. Dye-anchored MnO nanoparticles targeting tumor and inducing enhanced phototherapy effect via mitochondria-mediated pathway. Small. 2018;14(36):1801008. doi:10.1002/smll.201801008

55. He DG, He XX, Wang KM, et al. Redox-responsive degradable honeycomb manganese oxide nanostructures as effective nanocarriers for intracellular glutathione-triggered drug release. Chem Commun. 2015;51(4):776-779. doi:10.1039/C4CC08172B

56. Hu H, Dai AT, Sun J, et al. Aptamer-conjugated Mn3O4@SiO2 core-shell nanoprobes for targeted magnetic resonance imaging. Nanoscale. 2013;5(21):10447-10454. doi:10.1039/c3nr03490a

57. Yang X, Zhou Z, Wang L, Tang C, Yang H, Yang S. Folate conjugated Mn3O4@SiO2 nanoparticles for targeted magnetic resonance imaging in vivo. Mater Res Bull. 2014;57:97-102. doi:10.1016/j.materresbull.2014.05.023

58. Wang P, Yang J, Zhou BQ, et al. Antifouling manganese oxide nanoparticles: synthesis, characterization, and applications for enhanced MR imaging of tumors. ACS Appl Mater Inter. 2017;9 (1):47-53. doi:10.1021/acsami.6b13844

59. Luo Y, Yang J, Li J, et al. Facile synthesis and functionalization of manganese oxide nanoparticles for targeted T1-weighted tumor MR imaging. Colloids and Surf B Biointerfaces. 2015;136:506-513. doi:10.1016/j.colsurfb.2015.09.053

60. Sun W, Zhang J, Zhang C, et al. Construction of hybrid alginate nanogels loaded with manganese oxide nanoparticles for enhanced tumor magnetic resonance imaging. ACS Macro Lett. 2018;7 (2):137-142. doi:10.1021/acsmacrolett.7b00999

61. Lee J, Kumari N, Kim SM, et al. Anchoring ligand-effect on bright contrast-enhancing property of hollow $\mathrm{Mn} 3 \mathrm{O} 4$ nanoparticle in T1weighted magnetic resonance imaging. Chem Mater. 2018;30 (12):4056-4064. doi:10.1021/acs.chemmater.8b00854

62. Guo W, Qi Y, Zhang Y, Ma L, Yu D, Zhan J. Biocompatible caramelized carbonaceous nanospheres supported paramagnetic ultrathin manganese oxide nanosheets via self-sacrificing reduction as a MRI contrast agent for liver imaging. Carbon. 2016;110:321329. doi:10.1016/j.carbon.2016.09.030

63. Xiao J, Tian XM, Yang C, et al. Ultrahigh relaxivity and safe probes of manganese oxide nanoparticles for in vivo imaging. Sci Rep. 2013;3:3424. doi:10.1038/srep03424

64. $\mathrm{Hu} \mathrm{H}$, Zhang $\mathrm{C}$, An L, et al. General protocol for the synthesis of functionalized magnetic nanoparticles for magnetic resonance imaging from protected metal-organic precursors. Chemistry. 2014;20 (23):7160-7167. doi:10.1002/chem.201305072

65. Li JC, Hu Y, Sun WJ, Luo Y, Shi XY, Shen MW. Facile preparation of hyaluronic acid-modified Fe3O4@Mn3O4 nanocomposites for targeted T-1/T-2 dual-mode MR imaging of cancer cells. RSC Adv. 2016;6(42):35295-35304. doi:10.1039/C6RA05648B

66. Kim MH, Son HY, Kim GY, Park K, Huh YM, Haam S. Redoxable heteronanocrystals functioning magnetic relaxation switch for activatable T-1 and T-2 dual-mode magnetic resonance imaging. Biomaterials. 2016;101:121-130. doi:10.1016/j.biomaterials.2016.05.054

67. Zhu JY, Li HS, Xiong ZJ, et al. Polyethyleneimine-coated manganese oxide nanoparticles for targeted tumor PET/MR imaging. ACS Appl Mater Inter. 2018;10(41):34954-34964. doi:10.1021/acsami.8b12355

68. Fonsatti E, Nicolay HJM, Altomonte M, Covre A, Maio M. Targeting cancer vasculature via endoglin/CD105: a novel antibody-based diagnostic and therapeutic strategy in solid tumours. Cardiovasc Res. 2010;86(1):12-19. doi:10.1093/cvr/cvp332

69. Zhan Y, Ehlerding EB, Shi S, et al. Intrinsically zirconium-89-labeled manganese oxide nanoparticles for in vivo dual-modality positron emission tomography and magnetic resonance imaging. $J$ Biomed Nanotechnol. 2018;14(5):900-909. doi:10.1166/jbn.2018.2498

70. Zhan Y, Zhan W, Li H, et al. In vivo dual-modality fluorescence and magnetic resonance imaging-guided lymph node mapping with good biocompatibility manganese oxide nanoparticles. Molecules. 2017;22(12):2208. doi:10.3390/molecules22122208
71. Fang C, Zhang M. Nanoparticle-based theragnostics: integrating diagnostic and therapeutic potentials in nanomedicine. $J$ Control Release. 2010;146(1):2-5. doi:10.1016/j.jconrel.2010.05.013

72. Wang A, Guo M, Wang N, et al. Redox-mediated dissolution of paramagnetic nanolids to achieve a smart theranostic system. Nanoscale. 2014;6(10):5270-5278. doi:10.1039/c3nr05687b

73. Zhang Y, Tan J, Long M, et al. An emerging dual collaborative strategy for high-performance tumor therapy with mesoporous silica nanotubes loaded with Mn3O4. J Mater Chem B. 2016;4 (46):7406-7414. doi:10.1039/C6TB01788F

74. Agostinis P, Berg K, Cengel KA, et al. Photodynamic therapy of cancer: an update. CA Cancer J Clin. 2011;61(4):250-281. doi:10.3322/ caac. 20114

75. Nafiujjaman M, Nurunnabi M, Kang S-H, Reeck GR, Khan HA, Lee Y-K. Ternary graphene quantum dot-polydopamine-mn3O4 nanoparticles for optical imaging guided photodynamic therapy and T1-weighted magnetic resonance imaging. $J$ Mater Chem B. 2015;3(28):5815-5823. doi:10.1039/C5TB00479A

76. Ding X, Liu JH, JQ L, et al. Polydopamine coated manganese oxide nanoparticles with ultrahigh relaxivity as nanotheranostic agents for magnetic resonance imaging guided synergetic chemo-/photothermal therapy. Chem Sci. 2016;7(11):6695-6700. doi:10.1039/ c6sc01320a

77. Liu Y, Zhang G, Guo Q, et al. Artificially controlled degradable inorganic nanomaterial for cancer theranostics. Biomaterials. 2017;112:204-217. doi:10.1016/j.biomaterials.2016.10.028

78. Szatrowski TP, Nathan CF. Production of large amounts of hydrogen peroxide by human tumor cells. Cancer Res. 1991;51 (3):794-798.

79. Xu J, Han W, Yang P, et al. Tumor microenvironment-responsive mesoporous $\mathrm{MnO} 2$-coated upconversion nanoplatform for selfenhanced tumor theranostics. Adv Funct Mater. 2018;28 (36): 1803804. doi:10.1002/adfm.201803804

80. Lin LS, Song JB, Song L, et al. Simultaneous fenton-like ion delivery and glutathione depletion by $\mathrm{MnO} 2$-based nanoagent to enhance chemodynamic therapy. Angew Chem Int Edit. 2018;57 (18):4902-4906. doi:10.1002/anie.201712027

81. Evans SM, Koch CJ. Prognostic significance of tumor oxygenation in humans. Cancer Lett. 2003;195(1):1-16. doi:10.1016/s0304-3835(03) $00012-0$

82. Zhao ZL, Fan HH, Zhou GF, et al. Activatable fluorescence/MRI bimodal platform for tumor cell imaging via $\mathrm{MnO} 2$ nanosheetaptamer nanoprobe. J Am Chem Soc. 2014;136(32):11220-11223. doi:10.1021/ja5029364

83. Shi W, Song B, Shi W, et al. Bimodal phosphorescence-magnetic resonance imaging nanoprobes for glutathione based on $\mathrm{MnO} 2$ nanosheet-Ru(II) complex nanoarchitecture. ACS Appl Mater Interfaces. 2018;10(33):27681-27691. doi:10.1021/acsami.8b08872

84. Duan B, Wang D, Wu $\mathrm{H}$, et al. Core-shell structurized Fe3O4@C@MnO2 nanoparticles as pH responsive T1-T2* dualmodal contrast agents for tumor diagnosis. ACS Biomater Sci Eng. 2018;4(8):3047-3054. doi:10.1021/acsbiomaterials.8b00287

85. Eubank TD, Roberts RD, Khan M, et al. Granulocyte macrophage colony-stimulating factor inhibits breast cancer growth and metastasis by invoking an anti-angiogenic program in tumor-educated macrophages. Cancer Res. 2009;69(5):2133-2140. doi:10.1158/0008-5472. CAN-08-1405

86. Chen Y, Ye D, Wu M, et al. Break-up of two-dimensional MnO2 nanosheets promotes ultrasensitive $\mathrm{pH}$-triggered theranostics of cancer. Adv Mater. 2014;26(41):7019-7026. doi:10.1002/adma. 201402572

87. Song M, Liu T, Shi C, Zhang X, Chen X. Bioconjugated manganese dioxide nanoparticles enhance chemotherapy response by priming tumor-associated macrophages toward M1-like phenotype and attenuating tumor hypoxia. ACS Nano. 2016;10(1):633-647. doi:10.1021/acsnano.5b06779 
88. Hao Y, Wang L, Zhang B, et al. Manganese dioxide nanosheetsbased redox/pH-responsive drug delivery system for cancer theranostic application. Int $J$ Nanomedicine. 2016;11:1759-1778. doi:10.2147/IJN.S98832

89. Hao Y, Wang L, Zhang B, et al. Multifunctional nanosheets based on folic acid modified manganese oxide for tumor-targeting theranostic application. Nanotechnology. 2016;27(2):025101. doi:10.1088/09574484/27/36/365202

90. Pan J, Wang Y, Pan H, et al. Mimicking drug-substrate interaction: a smart bioinspired technology for the fabrication of theranostic nanoprobes. Adv Funct Mater. 2017;27(3):1603440. doi:10.1002/ adfm. 201603440

91. Zhang M, Xing L, Ke H, et al. MnO2-based nanoplatform serves as drug vehicle and MRI contrast agent for cancer theranostics. ACS Appl Mater Interfaces. 2017;9(13):11337-11344. doi:10.1021/ acsami.6b15247

92. Meng L, Cheng Y, Gan S, et al. Facile deposition of manganese dioxide to albumin-bound paclitaxel nanoparticles for modulation of hypoxic tumor microenvironment to improve chemoradiation therapy. Mol Pharm. 2018;15(2):447-457. doi:10.1021/acs. molpharmaceut.7b00808

93. Shi Y, Guenneau F, Wang X, Helary C, Coradin T. MnO2-gated nanoplatforms with targeted controlled drug release and contrastenhanced MRI properties: from 2D cell culture to 3D biomimetic hydrogels. Nanotheranostics. 2018;2(4):403-416. doi:10.7150/ ntno. 28046

94. Wu Y, Li D, Zhou F, et al. Versatile in situ synthesis of $\mathrm{MnO} 2$ nanolayers on upconversion nanoparticles and their application in activatable fluorescence and MRI imaging. Chem Sci. 2018;9 (24):5427-5434. doi:10.1039/c8sc00490k

95. Song R, Zhang M, Liu Y, et al. A multifunctional nanotheranostic for the intelligent MRI diagnosis and synergistic treatment of hypoxic tumor. Biomaterials. 2018;175:123-133. doi:10.1016/j. biomaterials.2018.05.018

96. Gottesman MM, Fojo T, Bates SE. Multidrug resistance in cancer: role of ATP-dependent transporters. Nat Rev Cancer. 2002;2(1):4858. doi: $10.1038 / \mathrm{nrc} 706$

97. Zhang $\mathrm{C}, \mathrm{Bu} \mathrm{WB}, \mathrm{Ni} \mathrm{DL}$, et al. Synthesis of iron nanometallic glasses and their application in cancer therapy by a localized fenton reaction. Angew Chem Int Edit. 2016;55(6):2101-2106. doi:10.1002/anie. 201510031

98. Turan IS, Yildiz D, Turksoy A, Gunaydin G, Akkaya EU. A bifunctional photosensitizer for enhanced fractional photodynamic therapy: singlet oxygen generation in the presence and absence of light. Angew Chem Int Edit. 2016;55(8):2875-2878. doi:10.1002/ anie. 201511345

99. Hao Y, Zhang B, Zheng C, et al. Multifunctional nanoplatform for enhanced photodynamic cancer therapy and magnetic resonance imaging. Colloids and Surf B Biointerfaces. 2017;151:384-393. doi:10.1016/j.colsurfb.2016.10.039

100. Meng HM, Lu LM, Zhao XH, et al. Multiple functional nanoprobe for contrast-enhanced bimodal cellular imaging and targeted therapy. Anal Chem. 2015;87(8):4448-4454. doi:10.1021/acs.analchem.5b00337

101. Chu CC, Lin HR, Liu H, et al. Tumor microenvironment-triggered supramolecular system as an in situ nanotheranostic generator for cancer phototherapy. Adv Mater. 2017;29(23):1605928. doi:10.1002/adma. 201700681

102. Sun QQ, He F, Sun CQ, et al. Honeycomb-satellite structured pH/ $\mathrm{H} 2 \mathrm{O} 2$-responsive degradable nanoplatform for efficient photodynamic therapy and multimodal imaging. ACS Appl Mater Inter 2018;10(40):33901-33912. doi:10.1021/acsami.8b10207

103. Liu H, Liu Y, Chu CC, et al. Intelligent albumin-stabilized manganese dioxide nanocomposites for tumor microenvironment responsive phototherapy. J Biomed Nanotechnol. 2017;13(10):1321-1332. doi:10.1166/jbn.2017.2450
104. Lin $\mathrm{T}$, Zhao X, Zhao S, et al. O2-generating $\mathrm{MnO} 2$ nanoparticles for enhanced photodynamic therapy of bladder cancer by ameliorating hypoxia. Theranostics. 2018;8(4):990-1004. doi:10.7150/ thno. 22465

105. Ma Z, Jia X, Bai J, et al. MnO2Gatekeeper: an Intelligent and O2evolving shell for preventing premature release of high cargo payload core, overcoming tumor hypoxia, and acidic H2O2-sensitive MRI. Adv Funct Mater. 2017;27(4):1604258. doi:10.1002/ adfm.201604258

106. Liu J, Du P, Liu T, et al. A black phosphorus/manganese dioxide nanoplatform: oxygen self-supply monitoring, photodynamic therapy enhancement and feedback. Biomaterials. 2019;192:179-188. doi:10.1016/j.biomaterials.2018.10.018

107. He ZM, Xiao Y, Zhang JR, Zhang PH, Zhu JJ. In situ formation of large pore silica-MnO2 nanocomposites with $\mathrm{H}+/ \mathrm{H} 2 \mathrm{O} 2$ sensitivity for $\mathrm{O}-2$ elevated photodynamic therapy and potential MR imaging. Chem Commun. 2018;54(24):2962-2965. doi:10.1039/C7CC09532E

108. Zhu W, Zhang L, Yang Z, et al. An efficient tumor-inducible nanotheranostics for magnetic resonance imaging and enhanced photodynamic therapy. Chem Eng J. 2019;358:969-979. doi:10.1016/j.cej.2018.10.102

109. Liang RJ, Liu LL, He HM, et al. Oxygen-boosted immunogenic photodynamic therapy with gold nanocages@manganese dioxide to inhibit tumor growth and metastases. Biomaterials. 2018;177:149 160. doi:10.1016/j.biomaterials.2018.05.051

110. Hao YW, Zhang BX, Zheng CX, et al. Multifunctional nanoplatform for enhanced photodynamic cancer therapy and magnetic resonance imaging. Colloid Surf B. 2017;151:384-393. doi:10.1016/j.colsurfb.2016.10.039

111. Hu DR, Chen LJ, Qu Y, et al. Oxygen-generating hybrid polymeric nanoparticles with encapsulated doxorubicin and chlorin e6 for trimodal imaging-guided combined chemo-photodynamic therapy. Theranostics. 2018;8(6):1558-1574. doi:10.7150/thno.22989

112. Xu JT, Han W, Yang PP, et al. Tumor microenvironment-responsive mesoporous $\mathrm{MnO} 2$-coated upconversion nanoplatform for selfenhanced tumor theranostics. Adv Funct Mater. 2018;28 (36):1803804. doi:10.1002/adfm.201803804

113. Bi HT, Dai YL, Yang PP, et al. Glutathione and $\mathrm{H} 2 \mathrm{O} 2$ consumption promoted photodynamic and chemotherapy based on biodegradable MnO2-Pt@Au-25 nanosheets. Chem Eng J. 2019;356:543-553. doi:10.1016/j.cej.2018.09.076

114. Zhang C, Chen W-H, Liu L-H, Qiu W-X, Yu W-Y, Zhang X-Z. An $\mathrm{O} 2$ self-supplementing and reactive-oxygen-species-circulating amplified nanoplatform via $\mathrm{H} 2 \mathrm{O} / \mathrm{H} 2 \mathrm{O} 2$ splitting for tumor imaging and photodynamic therapy. Adv Funct Mater. 2017;27 (43):1700626. doi:10.1002/adfm.v27.43

115. Deng YY, Li ED, Cheng XJ, et al. Facile preparation of hybrid core-shell nanorods for photothermal and radiation combined therapy. Nanoscale. 2016;8(7):3895-3899. doi:10.1039/c5nr09102k

116. Fan WP, Yung B, Huang P, Chen XY. Nanotechnology for multimodal synergistic cancer therapy. Chem Rev. 2017;117(22):1356613638. doi:10.1021/acs.chemrev.7b00258

117. Chen XY, Gambhlr SS, Cheon J. Theranostic Nanomedicine Accounts Chem Res. 2011;44(10):841. doi:10.1021/ar200231d

118. Liu Z, Zhang SJ, Lin H, et al. Theranostic 2D ultrathin MnO2 nanosheets with fast responsibility to endogenous tumor microenvironment and exogenous NIR irradiation. Biomaterials. 2018;155:54-63. doi:10.1016/j.biomaterials.2017.11.015

119. Fu DD, Ding XG, Wu J, Li CY, Wang QB, Jiang J. Cationic polyelectrolyte mediated synthesis of mno2-based core-shell structures as activatable MRI theranostic platform for tumor cell ablation. Part Part Syst Char. 2018;35(7):1800078. doi:10.1002/ppsc.201800078

120. Cai XJ, Gao W, Ma M, et al. A Prussian blue-based core-shell hollow-structured mesoporous nanoparticle as a smart theranostic agent with ultrahigh $\mathrm{pH}$-responsive longitudinal relaxivity. $A d v$ Mater. 2015;27(41):6382-6389. doi:10.1002/adma.201503381 
121. Chen WH, Luo GF, Lei Q, et al. Overcoming the heat endurance of tumor cells by interfering with the anaerobic glycolysis metabolism for improved photothermal therapy. ACS Nano. 2017;11(2):14191431. doi:10.1021/acsnano.6b06658

122. Jin $\mathrm{LH}$, Liu JH, Tang $\mathrm{Y}$, et al. $\mathrm{MnO} 2$-functionalized Co-P nanocomposite: a new theranostic agent for $\mathrm{pH}$-triggered T-1/T-2 dualmodality magnetic resonance imaging-guided chemo-photothermal synergistic therapy. ACS Appl Mater Inter. 2017;9(48):4164841658. doi:10.1021/acsami.7b10608

123. Li SN, Zhang LY, Chen XJ, et al. Selective growth synthesis of ternary janus nanoparticles for imaging-guided synergistic chemo- and photothermal therapy in the second NIR window. ACS Appl Mater Inter. 2018;10(28):24137-24148. doi:10.1021/acsami.8b06527

124. Zhang TT, $\mathrm{Xu} \mathrm{CH}$, Zhao W, et al. A redox-activated theranostic nanoagent: toward multi-mode imaging guided chemo-photothermal therapy. Chem Sci. 2018;9(33):6749-6757. doi:10.1039/c8sc02446d

125. Yang GB, Zhang R, Liang $C$, et al. Manganese dioxide coated WS2@Fe3O4/sSiO(2) nanocomposites for pH-responsive MR imaging and oxygen-elevated synergetic therapy. Small. 2018;14 (2):1702664. doi:10.1002/smll.201702664

126. Cao $\mathrm{Y}$, Meng $\mathrm{XD}$, Wang $\mathrm{DD}$, et al. Intelligent $\mathrm{MnO} 2 / \mathrm{Cu} 2-\mathrm{xS}$ for multimode imaging diagnostic and advanced single-laser irradiated photothermal/photodynamic therapy. ACS Appl Mater Inter. 2018;10(21):17732-17741. doi:10.1021/acsami.8b05050
127. Rosenholm JM, Korpi RM, Lammentausta E, et al. Novel, fastprocessed crystalline and amorphous manganese oxide nanoparticles for stem cell labeling. Inorg Chem Front. 2015;2(7):640-648. doi:10.1039/C5QI00033E

128. Ren SS, Yang J, Ma L, et al. Ternary-responsive drug delivery with activatable dual mode contrast-enhanced in vivo imaging. ACS Appl Mater Inter. 2018;10(38):31947-31958. doi:10.1021/ acsami.8b10564

129. Gao H, Liu X, Tang W, et al. (99m)Tc-conjugated manganesebased mesoporous silica nanoparticles for SPECT, pH-responsive MRI and anti-cancer drug delivery. Nanoscale. 2016;8(47):1957319580. doi:10.1039/c6nr07062k

130. Zhang SJ, Qian XQ, Zhang LL, Peng WJ, Chen Y. Compositionproperty relationships in multifunctional hollow mesoporous carbon nanosystems for PH-responsive magnetic resonance imaging and on-demand drug release. Nanoscale. 2015;7(17):7632-7643. doi:10.1039/c5nr00451a

131. Dai C, Chen Y, Jing XX, et al. Two-dimensional tantalum carbide (MXenes) composite nanosheets for multiple imaging-guided photothermal tumor ablation. ACS Nano. 2017;11(12):1269612712. doi:10.1021/acsnano.7b07241
International Journal of Nanomedicine

\section{Publish your work in this journal}

The International Journal of Nanomedicine is an international, peerreviewed journal focusing on the application of nanotechnology in diagnostics, therapeutics, and drug delivery systems throughout the biomedical field. This journal is indexed on PubMed Central, MedLine, CAS, SciSearch ${ }^{\circledR}$, Current Contents ${ }^{\mathbb{B}} /$ Clinical Medicine,

\section{Dovepress}

Journal Citation Reports/Science Edition, EMBase, Scopus and the Elsevier Bibliographic databases. The manuscript management system is completely online and includes a very quick and fair peer-review system, which is all easy to use. Visit http://www.dovepress.com/ testimonials.php to read real quotes from published authors. 